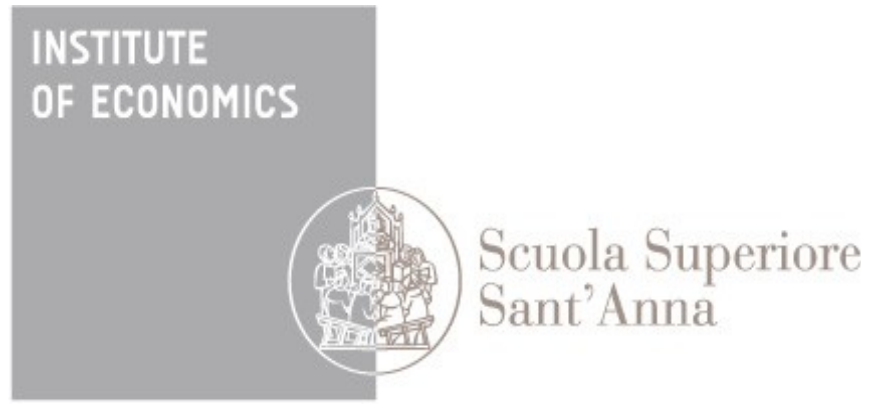

LEM | Laboratory of Economics and Management

Institute of Economics

Scuola Superiore Sant'Anna

Piazza Martiri della Libertà, 33 - 56127 Pisa, Italy ph. +3905088.33 .43$

institute.economics@sssup.it

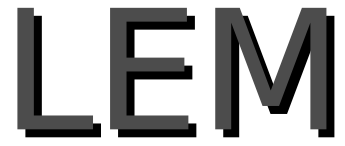

Working Paper Series

\title{
Uncertainty in Firm Valuation and a Cross-Sectional Misvaluation Measure
}

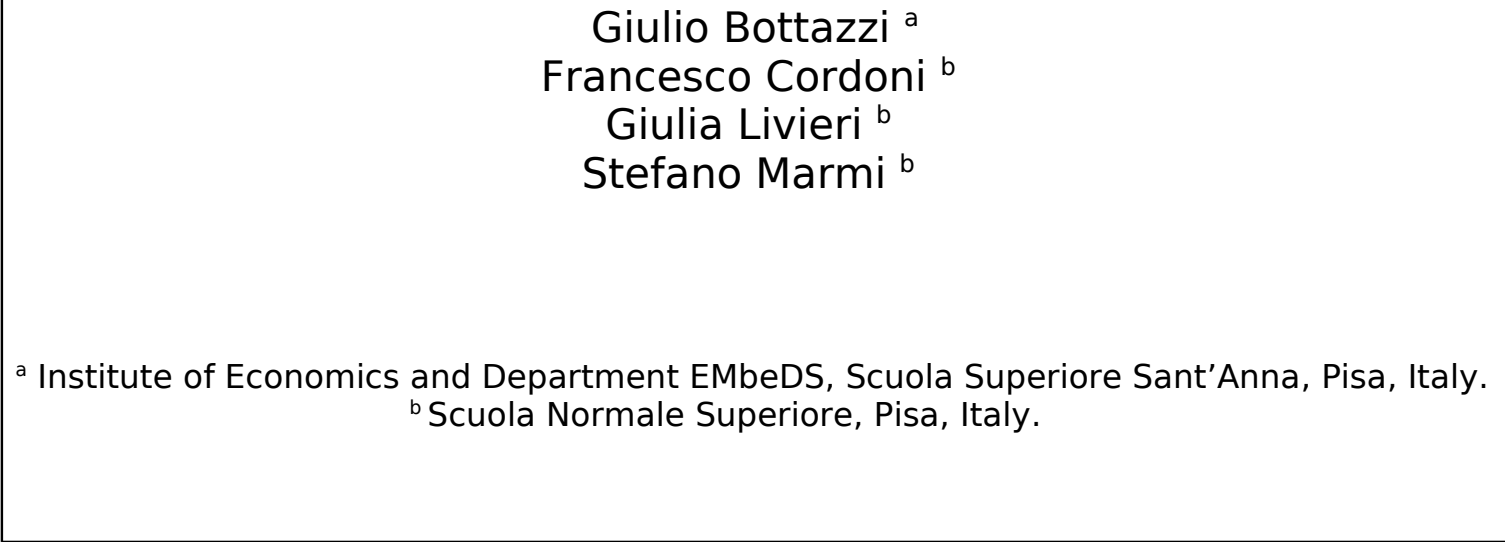

2020/15 June 2020

ISSN(ONLINE) 2284-0400 


\title{
Uncertainty in Firm Valuation and a Cross-Sectional Misvaluation Measure*
}

\author{
Giulio Bottazzi $^{\dagger a}$, Francesco Cordoni ${ }^{\ddagger b}$, Giulia Livieri ${ }^{\S b}$, and Stefano Marmi ${ }^{\uparrow b}$ \\ a Scuola Superiore Sant'Anna, \\ Piazza Martiri della Libertà, 33, 56127 Pisa Italy. \\ b Scuola Normale Superiore, \\ Piazza dei Cavalieri 7, 56123, Pisa, Italy.
}

Posted:May 31, 2020

${ }^{*}$ We are indebted to Giacomo Toscano and Iacopo Raffaelli for helpful comments and fruitful discussion. We are grateful to participants at the Quantitative Finance Workshop Qfw2020 (Napoli, January 28-30, 2020). We also thank David Hirshleifer and Danling Jiang for providing us the UMO factor data.

${ }^{\dagger}$ E-mail: giulio.bottazzi@santannapisa.it.

${ }^{\ddagger}$ E-mail: francesco.cordoni@sns.it.

$\S$ E-mail: giulia.livieri@sns.it

๑E-mail: stefano.marmi@sns.it. 


\begin{abstract}
In all investment decisions it is important to determine the degree of uncertainty associated with the valuation of a company. We propose an original and robust methodology to company valuation which replaces the traditional point estimate of the conventional Discounted Cash Flow (DCF) with a probability distribution of fair values. It hinges on two main ingredients: an econometric model for the company revenues and a set of firm-specific balance sheet relations that are estimated using historical data. The effectiveness and scope of our methodology are explored through a series of statistical exercises on publicly traded U.S. companies. We show that an uncertainty-adjusted indicator of mispricing, derived from the fair value distribution, is capable of predicting future abnormal returns. Then, we construct a new long-short valuation factor and we test that it is not redundant for describing average returns when used to augment traditional market factor models.
\end{abstract}

Keywords: Stochastic Discounted Cash Flow, Valuation Uncertainty, Valuation Factor, Kalman Filter.

JEL classification codes: G11, G17, G32. 


\section{Introduction}

Broadly speaking, the valuation literature presents three estimation approaches of the shareholder value. The first one is the "direct valuation" in which firm value is estimated directly from its expected cash flows, without any reference to the current price of other firms. Common examples are the dividend discount model (DDM), the residual income model (RIM) and the discounted cash flow model (DCF). The second one is the "relative valuation" in which firm value estimates are obtained by examining the pricing of comparable assets relative to some accounting variable. Finally, the third approach is constituted by the "contingent claim valuation" which applies option pricing models to evaluate a company; see Damodaran (2012) for further details.

In the present paper, we focus on what is probably the most fundamental direct valuation method, the DCF, which is widely employed by sell-side financial analyst and practitioners (e.g. Brown et al., 2015). The DCF is a three-step procedure. We first have to determine the stream of future cash flows, so reduce them to present value through a discount rate and, finally, compare the result with today's price. This approach attempts to capture with one number, the discount rate, two different effects: the time value of money and the uncertainty of future cash flows. However, primarily due to the intrinsic difficulty of estimating the future cash flows of a company, the value provided by DCF is likely to be affected by a considerable amount of uncertainty. Starting from this consideration, existing works have highlighted the necessity of developing probabilistic and statistical tools to extend the conventional DCF method to include some measure of uncertainty associated with the estimated value (Casey, 2001). To the best of our knowledge, despite its practical relevance, this problem has been the subject of surprisingly few academics studies. The general suggestion has been to perform Monte Carlo simulations of the underlying (accounting) variables starting from historically estimated correlation matrices (see French and Gabrielli (2005); Damodaran (2007)). This kind of Monte Carlo procedure is commonly used by analysts in investment banking studies (e.g Koller et al., 2010). In Ali et al. (2010); Gimpelevich (2011); Samis and Davis (2014) both scenario-based and simulation-based analyses are used together with the DCF for investment decisions in real-estate projects or for evaluating a specific market sector. Interestingly, in Viebig et al. (2008) the authors acknowledge that "Being intellectually honest, financial analysts can at best determine ranges or distribution of possible fundamental financial values but not exact price targets for stocks as future revenue growth rates, future operating margins and other inputs which go into DCF models cannot be predicted with certainty."

We propose a simple, general and theoretically grounded method, the Stochastic Discounted Cash Flow (SDCF) approach to replace the point estimate of the conventional DCF method with 
a proper random variable. The basic idea of SDCF is to consider a properly defined probability space suitable to describe the future cash flow dynamics. Should the correct cash flow process be known, the value computed by the standard DCF would be exactly the expectation of the random variable obtained by the SDCF. Clearly, the reliability of the method depends on the goodness of the data generating process one considers for future cash flows. The methodological novelty behind the $\mathrm{SDCF}$ is the adoption of a robust data generating process for the company's future cash flows that relies upon two observations. On the one hand, the basic source of cash flow, i.e., the revenues, has an important and volatile idiosyncratic component. On the other hand, while from an accounting point of view cash flow is a reconstructed variable that depends on a set of other, more fundamental, variables (e.g., amortization, cost of debts and taxes), all interacting and affecting the final realized cash flow in different degree, the structural relationship among these variables results stable in time. Starting from these premises, we employ a two-steps procedure to determine the future cash flow dynamic. Firstly, an econometric model of firm revenues is estimated at the level of a single firm and used in a Monte Carlo procedure to obtain the distribution of future sales. Then, all the other accounting variables are estimated as "margins" on the revenues by using historical-data. The end result is a fair value distribution that can be used to obtain both an estimate of the expected fair value of the company and of its degree of uncertainty.

What is the information content contained in the fair value distribution resulting from the SDCF approach? Using a volatility-adjusted mispricing z-score index - defined as the difference between the market price of the company and its expected fair value divided by the fair value distribution standard deviation - as a means to assess the misvaluation of a company, we investigate the long-standing issue that stock misvaluation is not instantaneously and fully eliminated by rational investors in the market, but rather is only corrected over time. In this respect, our study is related to the works of Hirshleifer and Jiang (2010) and Chang et al. (2013). In the former, authors construct a financing-based misvaluation factor ( $U M O$ ) from repurchase and new issue firms, after they identify common misvaluation across stocks based on firms' debt and equity financing. In the latter, instead, authors measure the misvaluation according to the difference between the observed market prices and predicted intrinsic values of individual stocks and form a misvaluation factor $(M S V)$ by measuring the returns on a factor-mimicking portfolio that goes long on undervalued stocks and short in overvalued stocks.

We begin by showing that the $z$-scores possess significant predictability power for one-quarter ahead excess returns when used to augment linear factor models routinely used in financial applications (e.g. the Fama-French three- and five-factors model (Fama and French, 1993, 2015)). Then, to assess the reliability of the $z$-score as a misvaluation indicator, we sort stocks into (appropriately 
defined) quantiles based on the empirical distribution function of the firms $z$-scores and we construct "Buy", "Hold" and "Sell" portfolios according to this quantile division. By computing the equally weighted daily return of these portfolios we find that the "Buy" portfolio earns a gross return higher than the "Sell" one. Motivated by this evidence, we form a long-short valuation factor $(L S V)$ by measuring the returns on a factor-mimicking portfolio that goes long on the most recommended stocks and short in the less recommended stocks. In particular, we note that: 1) Contrary to $M S V$, our factor is formed from companies' direct valuation. 2) Contrary to UMO, constructed through a top-down approach, our factor is constructed starting from individual balance sheet data, i.e. by a bottom-up approach. We show that $L S V$ is not redundant for describing average returns when added to the Fama French five-factors model (Fama and French, 2015) augmented by the momentum factor introduced in Carhart (1997), as well as by the UMO factor of Hirshleifer and Jiang (2010) $)^{1}$, thus confirming the stable presence of a significant degree of predictable mispricing in stock markets.

The rest of the article is organized as follows. In Section 2 we discuss the details of the SDCF model. In Section 3 we describe the database and variables used in our analysis. In Section 4 we introduce our misvaluation measure and we investigates the relation between stock misvaluation and future stock returns. Section 5 describes the formation of the misvaluation factor and the tests its return predictive power. Section 6 concludes the paper.

\section{The Model and The Methodology}

In DCF, the cash flow is distinguished between Unlevered Free Cash Flow (UFCF) and Levered Free Cash Flow (LCFC).2 The main difference between the two are expenses. Precisely, UFCF represents the cash flow available to the debt and equity holders after all expenses are paid off and reinvestments are made; LFCF, instead, represents the cash flow employed to pay out dividend and financial expansion investments. In our SDCF model we follow the approach which uses the former cash flow notion and we extend the usual point-wise UFCF DCF estimate by taking into account the intrinsic uncertainty about the future firm performance $3^{3}$

Now, we describe the SDCF method by presenting the main assumptions behind it and its main building blocks.

\footnotetext{
${ }^{1}$ At the moment of the writing of the present work we were not able to construct or find the $M S V$ factor.

${ }^{2}$ The former is known also as Free Cash Flow to Firm and the latter as Free Cash Flow to Equity.

${ }^{3}$ The UFCF DCF model employed in the present paper is in line with the one used by our data provider, Thomson Reuters Eikon, Datastream.
} 


\subsection{The SDCF method}

In what follows, we assume that all the random quantities are defined on a filtered probability space $\left(\Omega, \mathcal{F},\left(\mathcal{F}_{t}\right), \mathcal{P}\right)$. In addition, we denote with small (resp. capital) letters all the deterministic (resp. random) quantities. In the standard DCF method, the (present) value $v_{0}$ of a firm is defined as:

$$
v_{0}=\sum_{t=1}^{\infty} \frac{\mathbb{E}\left[C F_{t}\right]}{\prod_{s=1}^{t}\left(1+k_{s}\right)},
$$

where $C F_{t}$ denotes the firm's cash flow at time $t, \mathbb{E}[\cdot]$ denotes the conditional expected value operator based on the information available at time 0 , and $k_{s}, 1 \leq s \leq t$, denotes the appropriate discount factor at time $s$. In accordance with a large stream of literature (see, e.g., Damodaran (2007)), we make the following two assumptions:

Assumption 1. The discount factors is costant for all time and it is denoted by $k$.

Assumption 2. There exists a date $T>0$ and a rate $g$, with $0<g<k$ and $k$ as in Assumption 1. called "perpetual growth rate" such that

$$
C F_{t+1}=C F_{t} \cdot(1+g), \forall t \geq T \text {. }
$$

Under Assumption (1) and (2) the infinite summation in Eq. (1) can be rewritten as:

$$
v_{0}=\sum_{t=1}^{T} \frac{\mathbb{E}\left[C F_{t}\right]}{(1+k)^{t}}+\frac{\mathbb{E}\left[C F_{T}\right](1+g)}{(1+k)^{T}(k-g)},
$$

where the second term multiplied by $(1+k)^{T}$ is the terminal value $(T V)$. In Eq. (2), $v_{0}$ is a single point estimate because the uncertainty associated to the future firms' performance and to the evaluation process itself is summarized by the expected value of future cash flow. In SDCF, the single point estimate $v_{0}$ is replaced by the realization of a random variable $V_{0}$ such that $\mathbb{E}\left[V_{0}\right]=v_{0}$. In particular, in this framework, Eq. (2) can be rewritten $\forall \omega \in \Omega$ as:

$$
V_{0}(\omega)=\sum_{t=1}^{T} \frac{C F_{t}(\omega)}{(1+k)^{t}}+\frac{C F_{T}(\omega)(1+g)}{(1+k)^{T}(k-g)}
$$

The previous equation implies that the main building block in the definition of $V_{0}$ is a reliable description of the future cash flow generating process $C F_{t}$. However, the cash flow is on its own a reconstructed accounting variable, which depends on a set of other more fundamental variables. 
Specifically, we define for each time $t$ the UFCF as the difference between the sum of Net Operating Profit After Tax (NOPAT) and Depreciation and Amortization (D\&A) and the sum of Capital Expenditure $(C A P E X)$ and Change in the Working Capital (WC), (see, e.g., Damodaran, 2007, 2012):

$$
U F C F_{t}:=N O P A T_{t}+D \& A_{t}-C A P E X_{t}-\Delta W C_{t}
$$

where $\Delta W C_{t}=W C_{t}-W C_{t-1}, N O P A T_{t}=(E B I T D A-D \& A) \cdot\left(1-\tau_{0}\right), E B I T D A$ represents Earning Before Interest, Taxes, Depreciation, and Amortization and $\tau_{0}$ represents the marginal tax rate. A detailed description of these accounting variables is reported in Appendix A.

The interaction between these variables and the cash flow is manyfold and so, in order to obtain a manageable model, we employ the following two-steps procedure. First, we express all the relevant accounting variables as margins with respect to the revenues. These margins are estimated in a firm-specific regression framework. Second, we propose an econometric model for the revenues' dynamic. This model is calibrated at the single firm level and is used in a Monte Carlo exercise in order to obtain a statistical description of the future revenues (and therefore of the future cash flow). The rationale behind this approach is that on the one hand, the relation between the relevant accounting variables and revenues constitutes a structural relationship that is likely to remain stable across time. Indeed, it is related to things like the cost of capital, the accounting standard and taxation laws. On the other hand, the revenues are an important idiosyncratic component at the single firm level, besides being an important driver of the growth of a firm.

We now first construct a reliable relation between the cash flow and the revenues, then we propose an econometric model for the latter. Discounting rates are discussed at the end of this section.

Cash flow and Revenues. Using Eq. (4), we define for each time $t, \overline{C F}_{t}$ as the sum between $N O P A T_{t}$ and $D \& A_{t}$ less $C A P E X_{t}$, i.e., $\overline{C F}_{t}=N O P A T_{t}+D \& A_{t}-C A P E X_{t}$. Therefore, $C F_{t}=$ $\overline{C F}_{t}-\triangle W C_{t}$. Nonetheless, NOPAT $, D \& A_{t}, C A P E X_{t}$ and $W C_{t}$ are customarily expressed as marginal quantities upon the revenues $\left(R E V_{t}\right)$, i.e.,

$$
\overline{C F}_{t}=\alpha \cdot R E V_{t}, \quad W C_{t}=\beta \cdot R E V_{t}
$$

so that

$$
C F_{t}:=(\alpha-\beta) \cdot R E V_{t}+\beta \cdot R E V_{t-1}
$$


A distinguishing difference between $\overline{C F}_{t}$ and $\Delta W C_{t}$ is the frequency at which they are updated. Precisely, the former is updated every quarter by using trailing twelve months data, while the latter refers to annual variables. Then, we estimate $\alpha$ and $\beta$ in the previous equantions through two different steps. First, we estimate $\alpha$ with the following regression of $\overline{C F}_{t}$ on $R E V_{t}$ :

$$
\left\{\begin{array}{l}
\overline{C F_{t}}=\alpha R E V_{t}+u_{t} \\
u_{t}=\varepsilon_{t}-\sum_{i=1}^{q} \theta_{i} \varepsilon_{t-i}, \quad \varepsilon_{t} \stackrel{d}{\sim} \mathcal{N}\left(0, \sigma^{2}\right),
\end{array}\right.
$$

where $\mathcal{N}\left(\mu, \sigma^{2}\right)$ denotes a Gaussian random variable with mean $\mu$ and variance $\sigma^{2}$. The number of lags $q$ is fixed by using standard information criteria (e.g., the Akaike Information Criterion (AIC)). Regression in Eq. (5) is first estimated over the time period FQ4 1992-FQ1 2009 and subsequently over the remaining periods by shifting the initial estimation window of one fiscal quarter. Second, following our data provider Thomson Reuters Eikon, Datastream database, we set the operating margin of $W C_{t}$ upon the revenues equal to the annual sample average of the historical working capital margin rate computed initially over the period 2006-2009, i.e., over the last three years and subsequently by shifting the initial window of one year. Hereafter, for sake of presentation, the description of the procedure is related to a specific period only. Letting $\hat{\alpha}$ and $\hat{\beta}$ be these estimates, then our measure of cash flow is given by

$$
C F_{t}=(\hat{\alpha}-\hat{\beta}) R E V_{t}+\hat{\beta} R E V_{t-1}
$$

i.e., the dynamic of cash flows are characterized in terms of revenues' dynamic. A statistical analysis assessing the reliability of the previous relations is reported in Appendix B.

The Revenues' Process. We consider three alternative firm level models for the revenues. To be clear, we are not searching for a revenues' common-structure to be identified in a cross-sectional fashion, but rather we are interested in a firm-specific model for the revenues. Because we use trailing twelve-months data, we neglect in our models seasonal characteristics. The three alternative models are: let $y_{t}=\log \left(R E V_{t}\right)$,

a) Model 1 or stationary model:

$$
\left(1-\sum_{k=1}^{p} a_{k} L^{k}\right)(1-L) y_{t}=\varepsilon_{t}, \quad \varepsilon_{t} \stackrel{d}{\sim} \mathcal{N}\left(0, \sigma_{\varepsilon}^{2}\right)
$$


where $L$ is the usual lag operator, i.e. $L y_{t}=y_{t-1}$.

b) Model 2 or local level model:

$$
\begin{aligned}
\text { (Observation equation) } y_{t}=\mu_{t}+\varepsilon_{t}, & \varepsilon_{t} \stackrel{d}{\sim} \mathcal{N}\left(0, \sigma_{\varepsilon}^{2}\right) \\
\text { (Local level) } \quad \mu_{t+1}=\mu_{t}+\eta_{t}, & \eta_{t} \stackrel{d}{\sim} \mathcal{N}\left(0, \sigma_{\eta}^{2}\right),
\end{aligned}
$$

where the shocks $\varepsilon_{t}$ and $\eta_{t}$ are independent.

c) Model 3 or local linear trend model:

$$
\begin{array}{rlrl}
\text { (Observation equation) } y_{t} & =\mu_{t}+\varepsilon_{t}, & & \varepsilon_{t} \stackrel{d}{\sim} \mathcal{N}\left(0, \sigma_{\varepsilon}^{2}\right) \\
\text { (Local trend) } & \mu_{t+1}=\mu_{t}+\nu_{t}+\eta_{t}, & \eta_{t} \stackrel{d}{\sim} \mathcal{N}\left(0, \sigma_{\eta}^{2}\right) \\
\text { (Time-varying slope) } & \nu_{t+1}=\nu_{t}+\zeta_{t}, & & \zeta_{t} \stackrel{d}{\sim} \mathcal{N}\left(0, \sigma_{\zeta}^{2}\right),
\end{array}
$$

where the three innovations $\varepsilon_{t}, \eta_{t}$ and $\zeta_{t}$ are independent.

Model 1 assumes that the first difference of log-revenues are stationary and described by an $\operatorname{AR}(p)$ model, with the lag $p$ selected (again) according to AIC. Model 2 and Model 3 assume that the $\log$-revenues $y_{t}$ depend upon non observable state variables, the local trend $\mu_{t}$ and the time varying slope $\nu_{t}$, and represent two alternative models when the differenced time-series of revenues, $\Delta y_{t}$, are not stationary. These models are estimated in their state-space form using the Kalman filter, which is used to estimate the parameters of the models and the time series of the unobservable state variables (see, e.g., Harvey (1990) and Durbin and Koopman (2012) for further details). Note that because Model 2 is nested in Model 3, we can use the likelihood ratio test to select the best between the two. Once one model among these has been chosen, we compute a forecast of future log-revenues, and therefore of future cash-flow, by employing a bootstrap procedure. All details on this procedure are available upon request. They are omitted here for sake of conciseness. Appendix B reports analysis on the goodness of fit of the models proposed for the log-revenues (Model 1, Model 2 and Model 3) and a comparison against the simple autoregressive model of order one $\operatorname{AR}(1)$.

The Discounting and Perpetual growth rate. Future trajectories of cash flow are discounted back using the discount rate $k$ (see Eq. (3p). This discount rate is called Weighted Average Cost 
of Capital (WACC) and it is defined as:

$$
k=k_{e} w_{e}+k_{d} w_{d}+k_{p} w_{p}, \quad w_{e}+w_{d}+w_{p}=1
$$

where $k_{e}$ represents the cost of equity, $k_{d}$ is the after-tax cost of debt and $k_{p}$ is the cost of preferred stocks; $w_{e}, w_{d}$ and $w_{p}$ are the related weights. These values are provided directly from Thomson Reuters Eikon, Datastream database and we refer to Damodaran $(2010,2012)$ for a detailed description of their computation. For sake of completeness and for the reader convenience, Table 15 in Appendix A reports summary statistics of the WACC for each quarter, as well as of the perpetual growth rate. Following an industry standard, the discount rate for the cash flow terminal value is computed by considering the fixed corporate tax rate instead of the individual tax rate, albeit the difference is minimal for all firms and all years considered 4 The perpetual growth rate $g$ is determined, as usual, by the riskless $T$-bond rate.

Before turning to the computation of the fair value distribution, let us clarify the non trivial issue concerning the discount rate of Eq. (3) when $C F_{t}$ is a stochastic process. Actualization is an elementary financial mathematics notion, related in particular to the concept of time value. If at a future time $t$ we are going to receive a certain quantity of money, then to evaluate that money today we have to discount it using the riskless interest rate $r$. However, future cash flows of a firm are not a certain quantity. A widespread technique is to raise the riskless rate $r$ with a risk premium $z$ to also discount for the intrinsic uncertainty of the (future) cash flow. This is what happens in the conventional DCF method, where the expected future cash flows are discounted with the so called cost of capital rate (see, e.g. Kruschwitz and Löfler, 2006, for a detailed discussion). Therefore, should the model for the $C F_{t}$ accounts in full for the intrinsic uncertainty of the latter, the discount rate would be the riskless rate (see, e.g., Casey, 2001). However, this is not our case, in the sense that in our framework we assume that the cash flows of a specific firm are driven only by the idiosyncratic shocks of the revenues process, without accounting, for instance, for any possible co-integration with other firms. Then, we continue to use the same discount rate employed in the conventional DCF in Eq. (2) also in Eq. (3)

The Fair Value Distribution. Since we employ a UFCF approach, $V_{0}$ in Eq. (3) represents the enterprise value of a company. In order to compute the equity fair value, we have to remove,

\footnotetext{
${ }^{4}$ For the sake of completeness, if we denote the discounting rate related to the terminal value by $k_{T V}$, then $T V=\frac{C F_{T}(1+g)}{\left(k_{T V}-g\right)}$ and it is discounted by $\left(1+k_{T V}\right)^{T}$.

${ }^{5}$ We also note that our choice agrees with that made in Ali et al. (2010), Razgaitis $(2009)$ chapter 8; French and Gabrielli (2005) Dayananda et al. (2002)) where the use of Monte Carlo simulation in DCF is discussed.
} 
i.e., subtract, the current value of "debt". More precisely, we define the equity fair value $V_{0}^{E q}$ as:

$$
V_{0}^{E q}=V_{0}-(T D-C s I+M I+P S)
$$

where $T D$ represents the Total Debt, used as a proxy for the market value of debt (a proxy used also by our data provider and suggested also by Damodaran (2007)), CsI the Cash and Short-term Investments, $M I$ the Minority Interest and PS denotes the Preferred Stock; we refer to Table 14 in Appendix A for a detailed description of these quantities. The distribution of the equity fair values is divided by the number of company's outstanding shares to obtain the so called fair value distribution, which now can be compare with the corresponding stock price. Since, this distribution is estimated by a Monte Carlo procedure, in the following we will consider the empirical fair value distribution instead of the true one. However, we will not make this distinction for the sake of simplicity.

Summarizing, the key steps of the SDCF methodology are the following:

i) Estimate the slope $\hat{\alpha}$ through the time-series regression (5) and the operating margin $\hat{\beta}$ of $W C_{t}$ upon the revenues.

ii) Determine the most reliable model for the log-revenues, choosing one among Model 1, Model 2 and Model 3.

iii) Compute each trajectory of $C F_{t}(\omega), \omega \in \Omega$ in Eq. (6) by replacing the trajectory for the revenues process, with the bootstrapped value $\operatorname{REV}_{t}(\omega)$ determined by either Model 1, Model 2 or Model 3.

iv) Discount back these trajectories with the appropriate discount rates.

Figure ?? shows two examples of the logarithm of the fair value distribution for Booking Holdings Inc. (ticker BKNG) and McCormick \& Company (ticker MKC) computed at different dates; the red dotted lines indicate the market price at the evaluation date.

\section{Data and Sample Selection Criteria}

While the SDCF model relies upon general considerations, many details of its implementation and validation depend on specific company level data. In this Section we review the different data sources we use to develop and test our methodology. All the data in the subsequent description are 

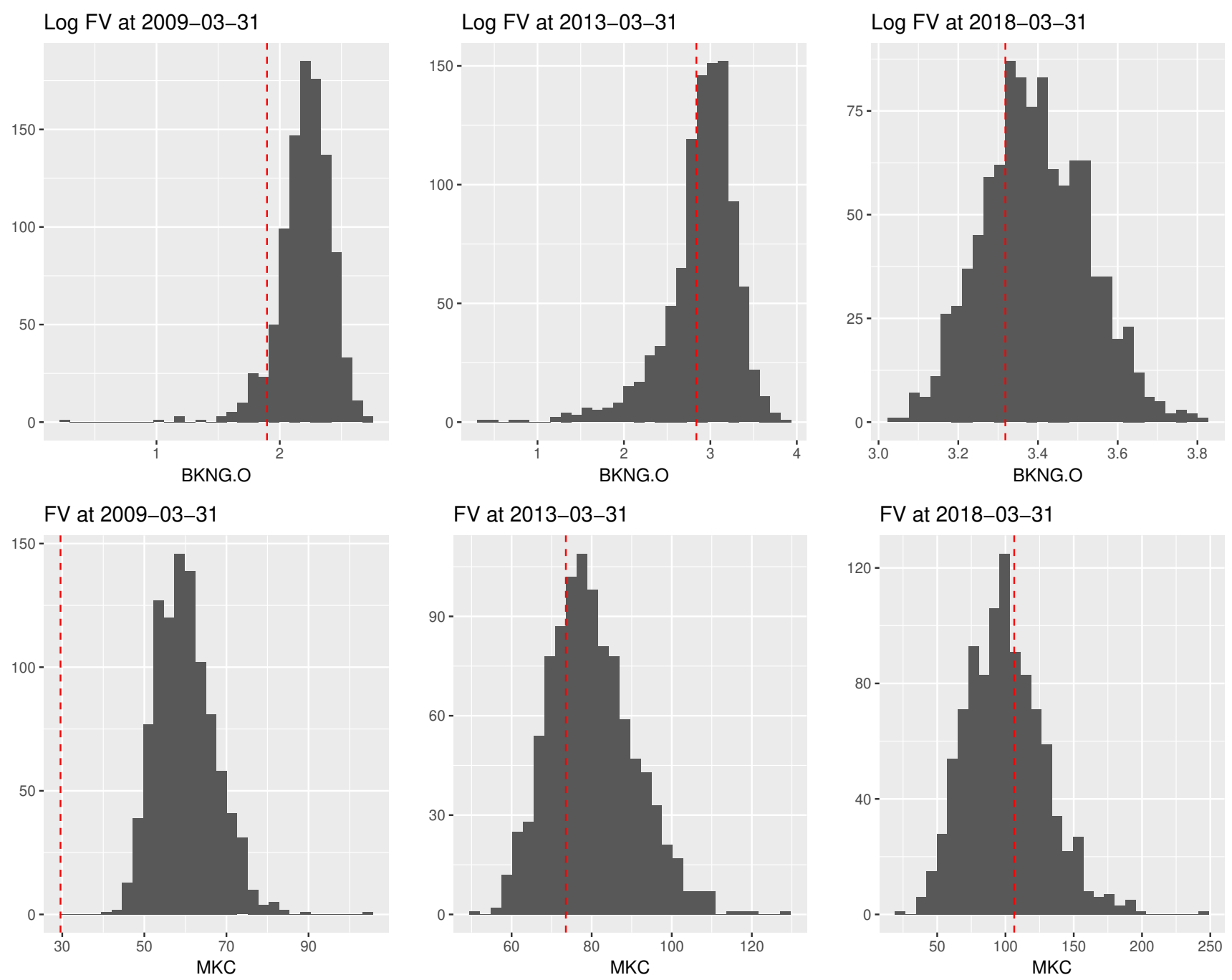

Figure 1: The Figure represents examples of the logarithm of the fair value distribution (labelled FV) for Booking Holdings Inc. (ticker BKNG) and McCormick \& Company (ticker MKC) computed at different dates; the red dotted lines indicate the market price at the evaluation date.

taken at a quarterly frequency.

The required equity prices, along with the corresponding fundamental data are collected from Thomson Reuters Eikon, Datastream database. Our initial sample covers the period December 1990-December 2017 and comprises all the 505 companies currently listed in the S\&P 500. We follow the usual practice and we exclude the 104 stocks belonging to the financial sector (they are labeled as financials according to the Industry Classification Benchmark (ICB)). These companies are subject to industry-specific regulations and present a peculiar capital structure which makes 
very difficult, if not meaningless, the estimation of cash flows. Note that we are left with 401 companies once financial codes are discarded. We then exclude firms with missing data and firms that are not included in the S\&P 500 over the entire period January 2009-December 2017, which is the time frame of our study for a total of 208 firms 1 In addition, we exclude 5 more firms from our universe because of lack of sufficient observations of the revenues before January 2009 as this may compromise the correct estimation of our econometric model. Finally, we discard 32 firms for which the coefficient of determination $\left(R^{2}\right)$ of the regression in Eq. (5) results to be less than $10 \%$ and 10 firms since we observe that for specific quarters, immediately after the financial crisis of 2008-2009, their estimated fair value distribution is negative 8 All together, these modifications leave us with a sample of 140 firms. As regards the heterogeneity, among the 140 firms we have: 17 firms in both the Oil \& Gas (ICB 1) and the Basic Material (ICB 1000) sector, 44 Industrial firms (ICB 2000), 22 Consumer Good firms (ICB 3000), 19 Healthcare firms (ICB 4000), 12 firms in the Consumer Service sector (ICB 5000), 3 firms in the Telecommunication sector (ICB 6000), 7 Utilities firms (ICB 7000) and 16 Technology Firms (ICB 9000). Table 1 reports for each ICB sector the percentage of stocks of our universe relative to the number of firms of the same sector in the S\&P 500 index. To check for possible sample distortion introduced by our selection criteria, Table 2 displays the percentage of stocks in each ICB sector relative to both our universe (first two columns) and the S\&P 500 (second two columns). Together, Tables 1 and 2 show that the final sample presents a great heterogeneity in terms of industry sectors and, importantly, reflects the composition of the index.

Table 1: Percentage of the stocks of our universe relatively to the S\&P500 for each ICB sector.

\begin{tabular}{llll}
\hline ICB sector & $(\%)$ & ICB sector & $(\%)$ \\
\hline 1 and 1000 & 36.17 & 5000 & 16.90 \\
2000 & 49.44 & 6000 & 100.00 \\
3000 & 37.93 & 7000 & 25.00 \\
4000 & 36.54 & 9000 & 30.19 \\
\hline
\end{tabular}

Table 3 presents summary statistics for our sample. Two "snapshots" are considered one referring to the beginning of the period, i.e. January 2009, and one to the end, i.e. December 2017.

\footnotetext{
${ }^{6}$ It is worth noting that because of the usage of the Kalman filter, a missing value for the revenues does not constitute a problem. Nonetheless, a missing data for the other fundamentals (e.g., EBITDA and CAPEX) complicates the reconstruction of the past free cash flow and/or the computation of the present value.

${ }^{7} \mathrm{We}$ also eliminate 6 double listing tickers.

${ }^{8}$ This is attributed to the bad performance during the crisis which affect the correct estimation of the true latent driver process on the next quarter.
} 
Table 2: Proportion of stocks in each ICB sector relative to both our universe (first and second column) and the S\&P500 (third and fourth column).

\begin{tabular}{|c|c|c|c|c|c|c|c|}
\hline \multicolumn{4}{|c|}{ Our Universe } & \multicolumn{4}{|c|}{ S\&P 500} \\
\hline ICB sector & $(\%)$ & ICB sector & $(\%)$ & ||| ICB sector & $(\%)$ & ICB sector & $(\%)$ \\
\hline 1 and 1000 & 12.14 & 5000 & 8.57 & 1 and 1000 & 11.72 & 5000 & 17.71 \\
\hline 2000 & 31.43 & 6000 & 2.14 & 2000 & 22.19 & 6000 & 0.75 \\
\hline 3000 & 15.72 & 7000 & 5.00 & 3000 & 14.46 & 7000 & 6.98 \\
\hline 4000 & 13.57 & 9000 & 11.43 & 4000 & 12.97 & 9000 & 13.22 \\
\hline
\end{tabular}

Data relative to December 2017 are reported between brackets. The table shows average and median values across the firms within the same sector of market capitalization, revenues and net income.

The data employed in the analysis of the returns of different portfolios within standard multifactor models (e.g., the market excess return and the momentum factor) are taken from the Kenneth R. French Data Library. ${ }^{9}$ In addition, since we set the terminal year $T$ to 5 , the perpetual growth rate $g$ is determined by the 5 -year $T$-bond rate obtained from the FRED (Federal Reserve Bank in St. Louis) database. Finally, the corporate tax rate for United States firms is provided by KPMG.

\section{Firm misvaluation measure $z$-score}

In this section, we introduce our measure of misvaluation. Let $\mu_{t}^{i}$ and $\sigma_{t}^{i}$ be the empirical mean and standard deviation of the log-fair value distribution of stock $i$ determined using our SDCF method at some time $t$ and let $p_{t}^{i}$ be the closing log-price at day $t$ of the same company. As mispricing indicator of company $i$ at time $t$ we take

$$
z_{t}^{i}:=\frac{p_{t}^{i}-\mu_{t}^{i}}{\sigma_{t}^{i}} \quad i \in\{1, \ldots, N\}
$$

that is the log-difference of the company's expected fair value and its price, divided by the standard deviation of the log-fair value distribution. In our indicator, the absolute level of of misvaluation, $\left|p_{t}^{i}-\mu_{t}^{i}\right|=\left|p_{t}^{j}-\mu_{t}^{j}\right|$, is amplified when the uncertainty associated to the valuation procedure is less uncertain.

First, we want to validate the $z$-score as a misvaluation measure. Toward this aim, we proceed in the following way. We sort stocks into (appropriately defined) quantiles based on the empirical

\footnotetext{
${ }^{9}$ https://mba.tuck.dartmouth.edu/pages/faculty/ken.french/data_library.html.
} 


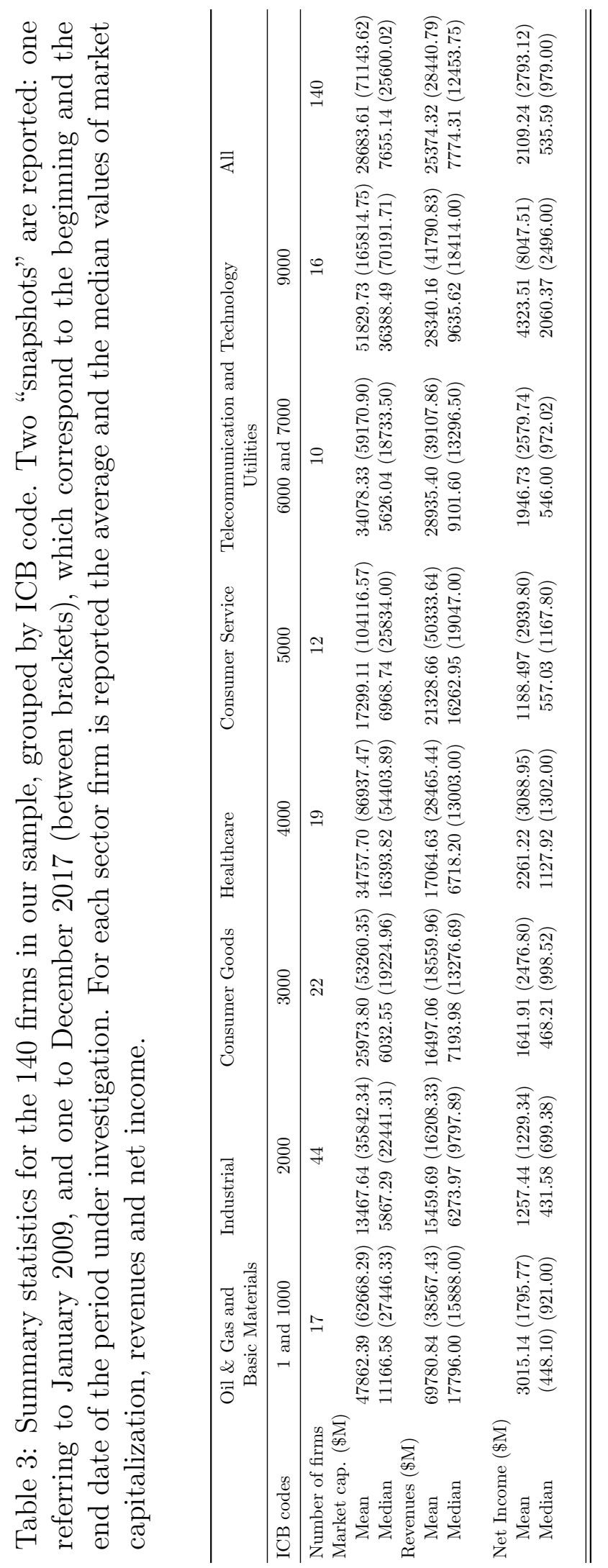

15 
distribution function $z$-score at the beginning of each semester, we construct "Buy", "Hold" and "Sell" portfolios according to this quantile division and we look at the performance of these portfolios over the examined time period. Precisely, let $\rho(\alpha)$ be the quantile function at level $\alpha$ of the empirical distribution of the $z$-scores $z^{i}, i \in\{1, \ldots, N\}$. If $z^{i}<\rho(0.4)$ the $i$-th firm is in the Buy portfolio, whereas we assign the $i$-th firm to the Sell portfolio if $z^{i} \geq \rho(0.6)$. The stocks such that $\rho(0.4)<z^{i}<\rho(0.6)$ constitute the Hold portfolio. For each portfolio we compute the equally weighted daily return and we compare its performance with the equally weighted portfolio formed by selecting all the stocks in our universe. The Sharpe and the Sortino ratios associated with the Buy portfolio are 1.43 and 1.87 respectively, which are higher than those of the Sell, Hold and Our universe portfolios. The same conclusions hold for the average annual return. The results are summarized in Table 4. In particular, by employing the test of Ledoit and Wolf (2008) and Ardia and Boudt (2018) we found a significant difference between the Sharpe ratios of Buy and Our universe portfolios with a t-Statistic of 2.98 and p-value of 3e-03. This first analysis is in support of the $z$-score as a means to asses the misvaluation of a company.

Table 4: Descriptive Statistics of Portfolios based on the z-scores measure. For each columns is reported the average number of firms, the average percentage of market capitalization respect to the our universe, the average annual log return, the annualized sharpe and sortino ratio, respectively.

\begin{tabular}{lllll}
\hline & Sell & Hold & Buy & Our Universe \\
\hline Avg. Number of Firms & 56 & 28 & 56 & 140 \\
Avg. Market Cap. (\%) & 34 & 16 & 50 & 100 \\
Avg. Annual Return(\%) & 17.63 & 18.07 & 20.83 & 19.04 \\
Sharpe Ratio & 1.05 & 1.15 & 1.43 & 1.24 \\
Sortino Ratio & 1.36 & 1.48 & 1.87 & 1.59 \\
\hline
\end{tabular}

At this point we assess whether the mispricing indicator $z_{t}^{i}$ possesses significant predictability power for the one-quarter ahead excess return when used to augment linear factor models. To this end, we need to introduce some notation. Let $q$ be the $q^{\text {th }}$-quarter, $q=1, \ldots, Q$, with $Q=37$; in addition, let $t_{q}$ be the starting date of such a quarter, and $\mu_{t_{q}}^{i}$ and $\sigma_{t_{q}}^{i}$ as above. For any fixed $q$, we compute the $z$-scores as defined in Eq. (7), where $t \in\left\{t_{q}, t_{q}+1, \ldots, t_{q+1}-1\right\}$ and $i \in\{1, \ldots, N\}$. Then we estimate the following factor model

$$
R_{i, t+t_{q}}^{\mathrm{EX}}=\alpha_{i}+\sum_{\ell=1}^{M} \beta_{i, \ell} F_{t+t_{q}}^{(\ell)}+\gamma \cdot z_{t}^{i}+e_{i, t+t_{q}}, \quad t \in\left\{t_{q}, \ldots, t_{q+1}-1\right\}, \quad i \in\{1, \ldots, N\}
$$




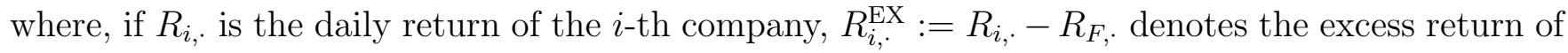
the firm $i$ over the risk-free rate $R_{F,}, M$ is the number of factors $F^{(\ell)}$ used to filter the raw returns, $\beta_{i, \ell}$ the exposure of the excess returns on the $\ell^{t h}$-factor, $\gamma$ is the common effect of the mispricing score and $e_{i,}$, the error term. We compare the market factor of Fama-French (Market Factor), the Fama and French (1993) three-factor model augmented by the momentum factor of Carhart (1997) (3 F-F + Mom) and the one-factor model computed using principal component analysis (First PC) ${ }^{10}$ The results are collected in Table 5. The estimated $\gamma$ 's are statistically significant and with a negative sign. This reflects the fact that misvaluation is corrected over time and price gradually converges to value. In particular, undervalued (resp. overvalued) stocks are characterized, on average, by higher (resp. lower) future excess returns.

Table 5: This table reports results for the fixed-effect time series regression in (8). $R^{2}$-within and $R^{2}$-overall are the adjusted- $R^{2}$. Coefficients resulting to be significant at $10 \%, 5 \%, 1 \%$ and $0.1 \%$ level are marked with '.', '*', '**' and '***' respectively. The sample period is April 1, 2009 to September 28, 2018 for a total of $Q=37$ quarters.

\begin{tabular}{llllll}
\hline & $\gamma$ & t-Statistic & p-value & $R^{2}$-within & $R^{2}$-overall \\
\hline Market Factor & -0.0033 & -3.0312 & $0.0025 * *$ & 0.2961 & 0.2963 \\
3 F-F + Mom & -0.0032 & -3.0332 & $0.0025 * *$ & 0.1291 & 0.1294 \\
First PC & -0.0035 & -2.8944 & $0.0038^{* *}$ & 0.3147 & 0.3149 \\
\hline
\end{tabular}

\section{The Valuation Factor}

As far as the $z$-score as a measure of misvaluation is concerned, in this section we form a misvaluation factor $L S V$ (Long Short Valuation) whose value at each day $t$ is given by the difference between the equal-weighted return of a portfolio that goes long on the most recommended stocks (i.e. the Buy portfolio) and short on the less recommended stocks (i.e. the Sell portfolio) of our universe. $L S V$ is computed over the period April 1, 2009 to September 28, 2018. It earns an average return of $2.70 \%$ ( $t$-Statistic $=1.49$ and $p$-value $=0.14$ ) and provides an annual Sharpe ratio of 0.48 .

We now explore the relation between $L S V$ and other popular return factors, i.e. the market factor $(M)$, the size factor $(S M B)$, the book-to-market factor $(H M L)$, the momentum factor $(M O M)$, the profitability factor $(R M W)$ and the investment factor $(C M A)$. We begin by running the excess

\footnotetext{
${ }^{10}$ We have also explored the Fama-French five-factor model (Fama and French, 2015) augmented by the momentum factor (Carhart, 1997). However, in this case, the number of parameters results too large with respect to the number of observations.
} 
return of $L S V$ on the just mentioned factors :

$$
\begin{aligned}
L S V_{t}-R_{F, t} & =\beta_{0}+\beta^{\mathrm{M}}\left(R_{M, t}-R_{F, t}\right)+\beta^{\mathrm{SMB}} S M B_{t}+\beta^{\mathrm{HML}} H M L_{t}+\beta^{\mathrm{MOM}} M O M_{t} \\
& +\beta^{\mathrm{RMW}} R M W_{t}+\beta^{\mathrm{CMA}} C M A_{t}+e_{t},
\end{aligned}
$$

where $e_{t}$ is a zero-mean residual. Empirical results are displayed in Table6. Treating the parameters

Table 6: This table reports results from the regression of the abnormal return $L S V-R_{F}$ on the factors $R_{M}-R_{F}, S M B, H M L, M O M, R M W, C M A$. Heteroskedasticity and autocorrelation (HAC) robust standard errors are shown in the second column $(S t d)$. The adjusted- $R^{2}$ is $28 \%$. Coefficients resulting to be significant at $10 \%, 5 \%, 1 \%$ and $0.1 \%$ level are marked with '.', '*', '**' and ' $* * *$ ' respectively. The number of observation is 2392. The sample is from April 1, 2009 to September 28, 2018.

\begin{tabular}{lllll}
\hline & Coeff & Std & $t$-Statistic & $p$-value \\
\hline Int & 0.018 & 0.006 & 3.075 & $2.13 \mathrm{e}-03^{* *}$ \\
$R_{M}-R_{F}$ & -0.118 & 0.008 & -15.569 & $<2 \mathrm{e}-16^{* * *}$ \\
SMB & -0.156 & 0.013 & -12.144 & $<2 \mathrm{e}-16^{* * *}$ \\
$H M L$ & -0.042 & 0.015 & -2.721 & $6.5 \mathrm{e}-03^{* *}$ \\
MOM & -0.138 & 0.008 & -16.129 & $<2 \mathrm{e}-16^{* * *}$ \\
RMW & 0.005 & 0.021 & 0.266 & 0.7900 \\
CMA & 0.055 & 0.025 & 2.238 & $0.0253^{*}$ \\
\hline
\end{tabular}

in (9) as true values rather than estimates, should the factor exposures capture all the variation in $\left(L S V_{t}-R_{F, t}\right)$ the intercept $\beta_{0}$ would be zero. In our results, the intercept is significantly different from zero at any conventional level and the adjusted $R^{2}$ is merely 0.28 ; this result points toward the existence of yet another anomaly hardly explained by well-accepted risk factors. In particular, following the (ambitious) interpretation of (9) suggested in Fama and French (2015) as "the regression equation for a version of Merton (1973)'s model in which up to five unspecified state variables lead to risk premium that are not captured by the market factor", the numbers in Table 6 suggest that $L S V$ provides a different combination of exposures to a new (unknown) state variable. Among the factors, the market, $S M B$ and $M O M$ are negative and statistically significant at any conventional level, whereas $R M W$ is not statistically significant. Less variation in $\left(L S V_{t}-R_{F, t}\right)$ is explained by $H M L$ and $C M A$. Also, Table 7 exhibits the Pearson correlation between $L S V$ and the other factors, whereas Figure 2 shows the scatter plot between $L S V_{t}$ and $R_{M, t}-R_{F, t}, L S V_{t}$ and $S M B_{t}$, and between $L S V_{t}$ and $M O M_{t}$, respectively.

We now turn to our primary task in this section, testing how well $L S V$ explain average excess returns on a equally weighted portfolio that is long in all the stocks of our universe. We denote the 
Table 7: This matrix reports the Pearson correlation between the misvaluation factor LSV and other Fama and French (2015) factors.

\begin{tabular}{|c|c|c|c|c|c|c|c|}
\hline & $L S F$ & $R_{M}-R_{F}$ & $S M B$ & $H M L$ & $M O M$ & $R M W$ & $C M A$ \\
\hline$L S F$ & - & -0.4045 & -0.3379 & -0.0352 & -0.2261 & 0.2288 & 0.0424 \\
\hline$R_{M}-R_{F}$ & & - & 0.3858 & 0.2996 & -0.1200 & -0.4609 & -0.0375 \\
\hline$S M B$ & & & - & 0.1027 & -0.0988 & -0.3579 & 0.0251 \\
\hline$H M L$ & & & & - & -0.4211 & -0.2982 & 0.4772 \\
\hline$M O M$ & & & & & - & 0.0924 & -0.0688 \\
\hline$R M W$ & & & & & & - & -0.0495 \\
\hline$C M A$ & & & & & & & - \\
\hline
\end{tabular}
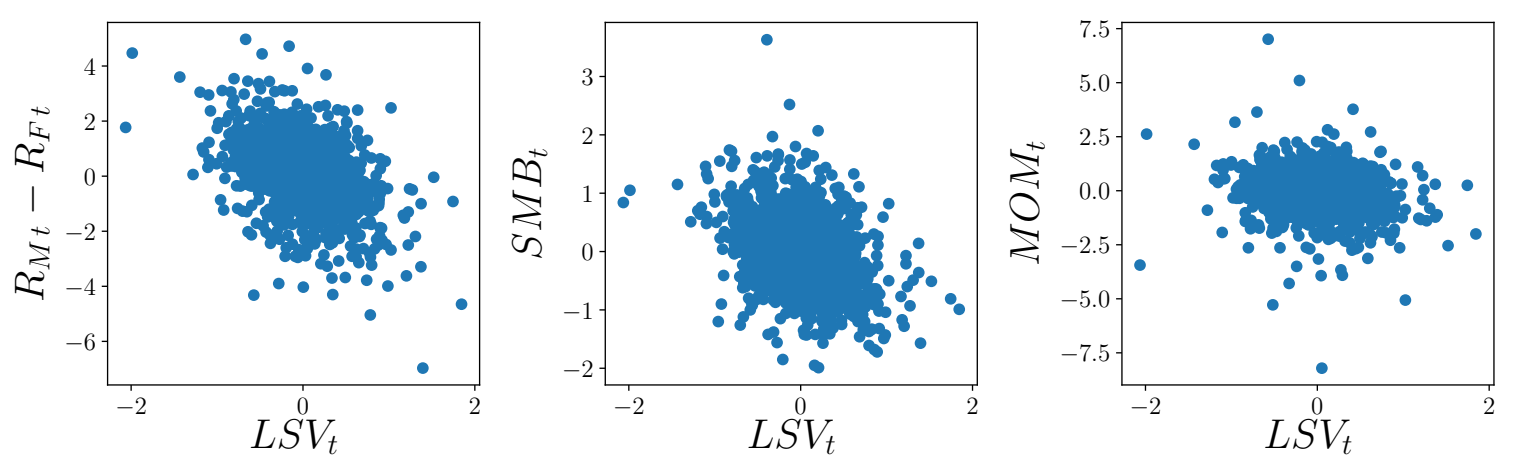

Figure 2: From left to right: Scatter plot between $L S V_{t}$ and $R_{M, t}-R_{F, t}, L S V_{t}$ and $S M B_{t}$, and between $L S V_{t}$ and $M O M_{t}$.

return of such a portfolio as $R_{U, t}$. We run the following regression.

$$
R_{U, t}-R_{F, t}=\beta_{0}+\beta^{\mathrm{LSV}} L S V_{t}+e_{t}
$$

where $\beta^{\mathrm{LSV}}$ denotes the exposure of the excess return to the valuation factor and $e_{t}$ is the usual error term. Any unusual return that is not explained by the valuation factor is captured by the intercept $\beta_{0}$. Empirical results are reported in Table 8 .

The intercept is significant and interestingly, the adjusted- $R^{2}$ attains up to $17 \%$, highlighting the importance of the new introduced valuation factor. The negative sign of $\beta^{\mathrm{LSV}}$ suggests that the excess return is achieved because of a good performance of the overvalued stocks of our universe.

Is the effect of $L S V$ on the excess returns hidden if we augment the regression in Eq. 10. with 
Table 8: This table reports results from the regression of the abnormal return $R_{U, t}-R_{F, t}$ on the factor $L S V$. Heteroskedasticity and autocorrelation $(H A C)$ robust standard errors are shown in the second column $(S t d)$. The adjusted- $R^{2}$ is $16.75 \%$. Coefficients resulting to be significant at $10 \%, 5 \%, 1 \%$ and $0.1 \%$ level are marked with '.', '*', '**' and '***' respectively. The number of observation is 2392. The sample is from April 1, 2009 to September 28, 2018.

\begin{tabular}{lllll}
\hline & Coeff & Std & t-Statistic & p-value \\
\hline Int & 0.092 & 0.018 & 5.085 & $3.97 \mathrm{e}-07^{* * *}$ \\
LSV & -1.126 & 0.051 & -21.956 & $<2 \mathrm{e}-166^{* * *}$ \\
\hline
\end{tabular}

other risk factors? To answer to this question, we run the following two time-series regressions:

$$
\begin{aligned}
R_{U, t}-R_{F, t} & =\beta_{0}+\beta^{\mathrm{M}}\left(R_{M, t}-R_{F, t}\right)+\beta^{\mathrm{SMB}} S M B_{t}+\beta^{\mathrm{HML}} H M L_{t}+\beta^{\mathrm{MOM}} M O M_{t} \\
& +\beta^{\mathrm{RMW}} R M W_{t}+\beta^{\mathrm{CMA}} C M A_{t}+e_{t}, \\
R_{U, t}-R_{F, t} & =\beta_{0}+\beta^{\mathrm{M}}\left(R_{M, t}-R_{F, t}\right)+\beta^{\mathrm{SMB}} S M B_{t}+\beta^{\mathrm{HML}} H M L_{t}+\beta^{\mathrm{MOM}} M O M_{t} \\
& +\beta^{\mathrm{RMW}} R M W_{t}+\beta^{\mathrm{CMA}} C M A_{t}+\beta^{\mathrm{LSV}} L S V_{t}+e_{t} .
\end{aligned}
$$

The former is the Fama-French five-factor model augmented by the momentum factor. The latter is obtained from the first one by adding $L S V$. For make it easier the presentation of the results, we denote the two model Six-factor and Seven-factor, respectively. The results are collected in Table 9 .

Importantly, the improvements offered by the Seven-factor model can be statistically tested by employing a likelihood ratio test. It results that the $\chi^{2}=59.89$ with a $p$-value of $1.00 e-14$. We note that in the Seven-factor model the $S M B$ coefficient is not significant as for the other factors. Its influence seems to be captured by $L S V$, a result not new in the empirical finance literature (see Fama and French, 2015). It is, therefore, interesting, to run the following time-series regression

$$
\begin{aligned}
R_{U, t}-R_{F, t} & =\beta_{0}+\beta^{\mathrm{M}}\left(R_{M, t}-R_{F, t}\right)+\beta^{\mathrm{LSV}} L S V_{t}+\beta^{\mathrm{HML}} H M L_{t}+\beta^{\mathrm{MOM}} M O M_{t} \\
& +\beta^{\mathrm{RMW}} R M W_{t}+\beta^{\mathrm{CMA}} C M A_{t}+e_{t},
\end{aligned}
$$

which is obtained from the Six-factor by replacing $S M B$ with $L S V$. We denote the previous model Six-factor(2). The results are, again, reported in Table 9. We emphasize that Six-factor(2) has a statistically significant better fit that the Six-factor one, as confirmed by the corresponding information criteria $A I C$ and $B I C$ (see the caption of Table 9p.

As an additional empirical exercise of this subsection, we run a two-factor model in which one 
factor is the $L S V$ and the other one is computed using principal component analysis. Precisely, $F_{t}^{(\mathrm{PCA})}$ is the first principal component extracted from the matrix of the daily returns of all the stocks of our universe over the entire time-period, which is, contrary to the other risk-factors, endogenous. Even in this case, $\beta^{\mathrm{LSV}}$ is significant at any conventional level.

To further assess robustness to our results, we make the following additional observations. The factor $L S V$ seems to share some information content with the $S M B$ factor. From Table 7 we observe that $L S V$ is correlated with the market, momentum and robust minus weak factor. Then, in order to investigate the unique information contained in $L S V$, we perform the time-series regressions (12) and (13) on an orthogonalized misvaluation factor, $L S V^{\perp}$, which is defined as the sum of a constant (i.e. the intercept), the risk-free rate and residuals extracted from the regression (9), i.e.,

$$
L S V^{\perp}:=\beta_{0}+R_{F, t}+e_{t}
$$

By construction, the orthogonalized misvaluation factor has zero correlation with the Fama-French and MOM factors. Therefore, we estimate the time-series regressions $(12)$ and $(13)$ by replacing $L S V$ with its orthogonalized version and the results are collected in Table11. Interestingly, the beta associated with $L S V^{\perp}$ continues to be statistically significant and negative even if the influence of the other factors has all been removed from $L S V^{\perp}$. In addition, we observe that $S M B$ is no longer non significant in the seven-factor model which was masked by the collinearity with $L S V$ in the previous regression. Moreover, the (new) Seven-factor provides a significant better fit than Sixfactor models according to likelihood ratio test and to both AIC and BIC criteria (see the caption of Table 11]

\footnotetext{
${ }^{11}$ The likelihood ratio test between the Six-factor and the Seven-factor model has a $\chi^{2}=59.89$ with a resulting p-value of 1e-14. The likelihood ratio test between the Six-factor(2) and Seven-factor has a $\chi^{2}=16.87$ with a resulting p-value of 3.99e-05.
} 
Table 9: This table reports results from regressions of the six-factor model, seven-factor model (top panel), and of the six-factor(2) model (bottom panel). Six-factor: the adjusted- $R^{2}$ is $97.55 \%$, the $A I C$ is -2220.33 and the $B I C$ is -2174.09 . Seven-factor: the adjusted- $R^{2}$ is $97.61 \%$, the $A I C$ is -2278.22 and the $B I C$ is -2226.20 . Six-factor(2): the adjusted- $R^{2}$ is $97.60 \%$, the $A I C$ is -2275.76 and the $B I C$ is -2229.52 . Heteroskedasticity and autocorrelation $(H A C)$ robust standard errors are shown in the Std column. Coefficients resulting to be significant at 10\%, 5\%, $1 \%$ and $0.1 \%$ level are marked with '.', '*', '**' and '***' respectively. The number of observation is 2392 . The sample is from April 1, 2009 to September 28, 2018.

\begin{tabular}{|c|c|c|c|c|c|c|c|c|}
\hline & \multicolumn{4}{|c|}{ Six - factor } & \multicolumn{4}{|c|}{ Seven - factor } \\
\hline & Coeff & $S t d$ & t-Statistic & p-value & Coeff & $S t d$ & t-Statistic & p-value \\
\hline Int & 0.0089 & 0.0031 & 2.86 & $4.33 \mathrm{e}-03^{* *}$ & 0.0105 & 0.0031 & 3.40 & $6.80 \mathrm{e}-04^{* * *}$ \\
\hline$R_{M}-R_{F}$ & 1.0161 & 0.0038 & 264.22 & $<2 \mathrm{e}-16 * * *$ & 1.0067 & 0.0039 & 252.494 & $<2 \mathrm{e}-16 * * *$ \\
\hline$S M B$ & 0.0265 & 0.0065 & 4.06 & $5.12 \mathrm{e}-05 * * *$ & 0.0140 & 0.0066 & 2.11 & $0.03493 *$ \\
\hline$H M L$ & -0.1562 & 0.0078 & -19.89 & $3.97 \mathrm{e}-07 * * *$ & -0.159 & 0.0077 & -20.55 & $<2 \mathrm{e}-16 * * *$ \\
\hline$M O M$ & -0.0576 & 0.0044 & -13.21 & $<2 \mathrm{e}-16 * * *$ & -0.0686 & 0.0045 & -15.14 & $<2 \mathrm{e}-16 * * *$ \\
\hline$R M W$ & 0.1889 & 0.01059 & 17.84 & $3.97 \mathrm{e}-07 * * *$ & 0.1893 & 0.01046 & 18.09 & $<2 \mathrm{e}-16 * * *$ \\
\hline$C M A$ & 0.3056 & 0.01267 & 24.11 & $3.97 \mathrm{e}-07 * * *$ & 0.3107 & 0.01253 & 24.75 & $<2 \mathrm{e}-16 * * *$ \\
\hline \multirow[t]{3}{*}{$L S V$} & - & - & - & - & -0.0801 & 0.01031 & -7.775 & $1.12 \mathrm{e}-14 * * *$ \\
\hline & \multicolumn{4}{|c|}{ Six - factor $(2)$} & & & & \\
\hline & Coeff & $S t d$ & $t$-Statistic & p-value & & & & \\
\hline Int & 0.0105 & 0.0031 & 3.424 & $6.20 \mathrm{e}-04 * * *$ & & & & \\
\hline$R_{M}-R_{F}$ & 1.008 & 0.0039 & 257.29 & $<2 \mathrm{e}-16 * * *$ & & & & \\
\hline$S M B$ & - & - & - & - & & & & \\
\hline$H M L$ & -0.1617 & 0.0077 & -20.965 & $<2 \mathrm{e}-16 * * *$ & & & & \\
\hline$M O M$ & -0.070 & 0.0044 & -15.68 & $<2 \mathrm{e}-16 * * *$ & & & & \\
\hline$R M W$ & 0.1843 & 0.010 & 18.075 & $<2 \mathrm{e}-16 * * *$ & & & & \\
\hline$C M A$ & 0.3124 & 0.012 & 25.019 & $<2 \mathrm{e}-16 * * *$ & & & & \\
\hline$L S V$ & -0.0853 & 0.010 & -8.53 & $<2 \mathrm{e}-16 * * *$ & & & & \\
\hline
\end{tabular}

Table 10: This table reports results from the regression of $R_{U, t}-R_{F, t}$ on the first principal component factor $F_{t}^{(p c a)}$ and on the valuation factor $L S V_{t}^{\perp}$. Heteroskedasticity and autocorrelation $(H A C)$ robust standard errors are shown in the second column $(S t d)$. The adjusted- $R^{2}$ is $99.31 \%$. The number of observation is 2392. The sample is from April 1, 2009 to September 28, 2018. Coefficients that result to be significant at $5 \%, 1 \%$ and at any conventional confidence levels are marked, respectively, with one, two and three stars.

\begin{tabular}{lllll}
\hline & Coeff & Std & t-Statistic & p-value \\
\hline Int & 0.078 & 0.0016 & 47.78 & $<2 \mathrm{e}-16^{* * *}$ \\
$F^{(p c a)}$ & 0.9659 & 0.0016 & 588.05 & $<2 \mathrm{e}-16^{* * *}$ \\
$L S V^{\perp}$ & 0.0642 & 0.0051 & 12.45 & $<2 \mathrm{e}-16^{* * *}$ \\
\hline
\end{tabular}


Table 11: This table reports results from regressions of the seven-factor model and of the Six factor(2) model, where $L S V^{\perp}$ is used instead of $L S V$. Seven-factor: the adjusted- $R^{2}$ is $97.61 \%$, the $A I C$ is -2278.22 and the $B I C$ is -2226.20 . Six-factor(2): the adjusted- $R^{2}$ is $97.59 \%$, the $A I C$ is -2263.35 and the $B I C$ is -2217.11 . Heteroskedasticity and autocorrelation $(H A C)$ robust standard errors are shown in the Std column. Coefficients resulting to be significant at 10\%, $5 \%$, $1 \%$ and $0.1 \%$ level are marked with '.', '*', '**' and '***' respectively. The number of observation is 2392. The sample is from April 1, 2009 to September 28, 2018.

\begin{tabular}{lllllllll}
\hline & \multicolumn{4}{c}{ Seven-factor } & \multicolumn{4}{c}{ Six-factor $(2)$} \\
& Coeff & Std & t-Statistic & p-value & Coeff & Std & t-Statistic & p-value \\
\hline Int & 0.0105 & 0.0031 & 3.40 & $6.82 \mathrm{e}-04^{* * *}$ & 0.0105 & 0.0031 & 3.37 & $7.55 \mathrm{e}-04^{* * *}$ \\
$R_{M}-R_{F}$ & 1.0161 & 0.0038 & 267.49 & $<2 \mathrm{e}-16^{* * *}$ & 1.021 & 0.0037 & 279.13 & $<2 \mathrm{e}-16^{* * *}$ \\
SMB & 0.0266 & 0.0065 & 4.10 & $4.13 \mathrm{e}-05^{* *}$ & - & - & - & - \\
$H M L$ & -0.1563 & 0.0078 & -20.14 & $<2 \mathrm{e}-16^{* * *}$ & -0.156 & 0.0077 & -20.69 & $<2 \mathrm{e}-16^{* * *}$ \\
$M O M$ & -0.0576 & 0.0044 & -13.38 & $<2 \mathrm{e}-16^{* * *}$ & -0.0592 & 0.0045 & -13.77 & $<2 \mathrm{e}-16^{* * *}$ \\
$R M W$ & 0.1889 & 0.0106 & 18.06 & $<2 \mathrm{e}-16^{* * *}$ & 0.1788 & 0.0105 & 17.52 & $<2 \mathrm{e}-16^{* * *}$ \\
$C M A$ & 0.3056 & 0.0127 & 24.41 & $<2 \mathrm{e}-16^{* * *}$ & 0.3098 & 0.0125 & 24.75 & $<2 \mathrm{e}-16^{* * *}$ \\
$L S V^{\perp}$ & -0.0801 & 0.0103 & -7.775 & $1.12 \mathrm{e}-14^{* * *}$ & -0.0801 & 0.0103 & -7.749 & $1.36 \mathrm{e}-14^{* * *}$ \\
\hline
\end{tabular}




\subsection{Comparison with UMO factor}

In this section, we compare the $L S V$ factor with the $U M O$ factor of Hirshleifer and Jiang (2010). We note that the UMO factor is available until December 30, 2016 at the time of the writing of the present work. As a first thing, we consider the regression (9) augmented with the UMO factor. The factor $H M L$ is not more statistically significant, whereas the $U M O$ factor is significant at any conventional level, see Table 12. As previously done, we compute the Pearson correlation between $U M O$ and $L S V$ which is equal to 0.094. In addition, Figure 3 shows the scatter plot between the $U M O$ and $L S V$, which suggests that the two misvaluation factors are orthogonal to each other.

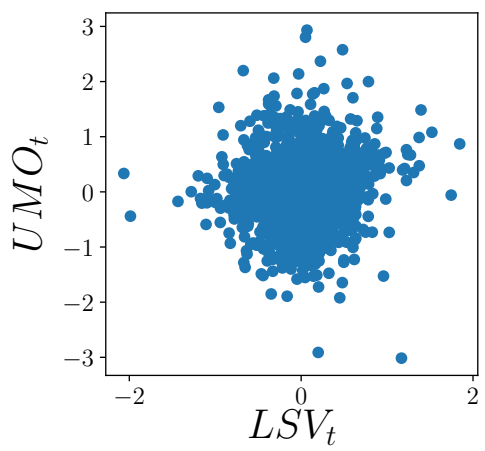

Figure 3: Scatter plot between $L S V_{t}$ and $U M O_{t}$.

Table 12: This table reports results from the regression of the abnormal return $L S V-R_{F}$ on the factors $R_{M}-R_{F}, S M B, H M L, M O M, R M W, C M A$ and $U M O$. Heteroskedasticity and autocorrelation (HAC) robust standard errors are shown in the second column $(S t d)$. The adjusted$R^{2}$ is $31 \%$. Coefficients resulting to be significant at $10 \%, 5 \%, 1 \%$ and $0.1 \%$ level are marked with '.', '*', '**' and '***' respectively. The number of observation is 1953. The sample is from April 1, 2009 to December 30, 2016.

\begin{tabular}{lllll}
\hline & Coeff & Std & t-Statistic & p-value \\
\hline Int & 0.0218 & 0.0070 & 3.1260 & $0.0018^{* *}$ \\
$R_{M}-R_{F}$ & -0.1196 & 0.0084 & -14.2400 & $<2 \mathrm{e}-16^{* * *}$ \\
SMB & -0.1866 & 0.0148 & -12.6200 & $<2 \mathrm{e}-16^{* * *}$ \\
$H M L$ & -0.0198 & 0.0185 & -1.0710 & 0.2844 \\
MOM & -0.1343 & 0.0096 & -14.0170 & $<2 \mathrm{e}-16^{* * *}$ \\
RMW & 0.0697 & 0.0267 & 2.6070 & $0.0092^{* *}$ \\
CMA & 0.0578 & 0.0299 & 1.9350 & 0.0532. \\
UMO & -0.0723 & 0.0156 & -4.6440 & $3.65 \mathrm{e}-06^{* * *}$ \\
\hline
\end{tabular}

Then, to further investigate the relation between this two factors we compare them among time. 
Following Chang et al. (2013) we interpret the variation of the absolute value of a misvaluation factor as the degree of misvaluation measured by the factor and we plot the daily absolute value of the logarithmic return of the $U M O$ and $L S V$ factor rescaled by their mean and standard deviation. Figure 4 shows how the $U M O$ factor attributes an high value of misvaluation to the period between 2015 and 2016 while for the $L S V$ it is the window between 2010 and 2011. This suggests that the two misvaluation factor are in some sense complementary to each other and it can be explained by looking the nature of the two factors. $U M O$ is based on a stock classification that looks the past events in the previous two years, see Hirshleifer and Jiang (2010) for further details, which can be identified as a top-down approach. On the other hand, the $L S V$ factor is constructed starting from individual balance sheet data (bottom-up approach) and it is based on a cross-section measure provided by the SDCF method.
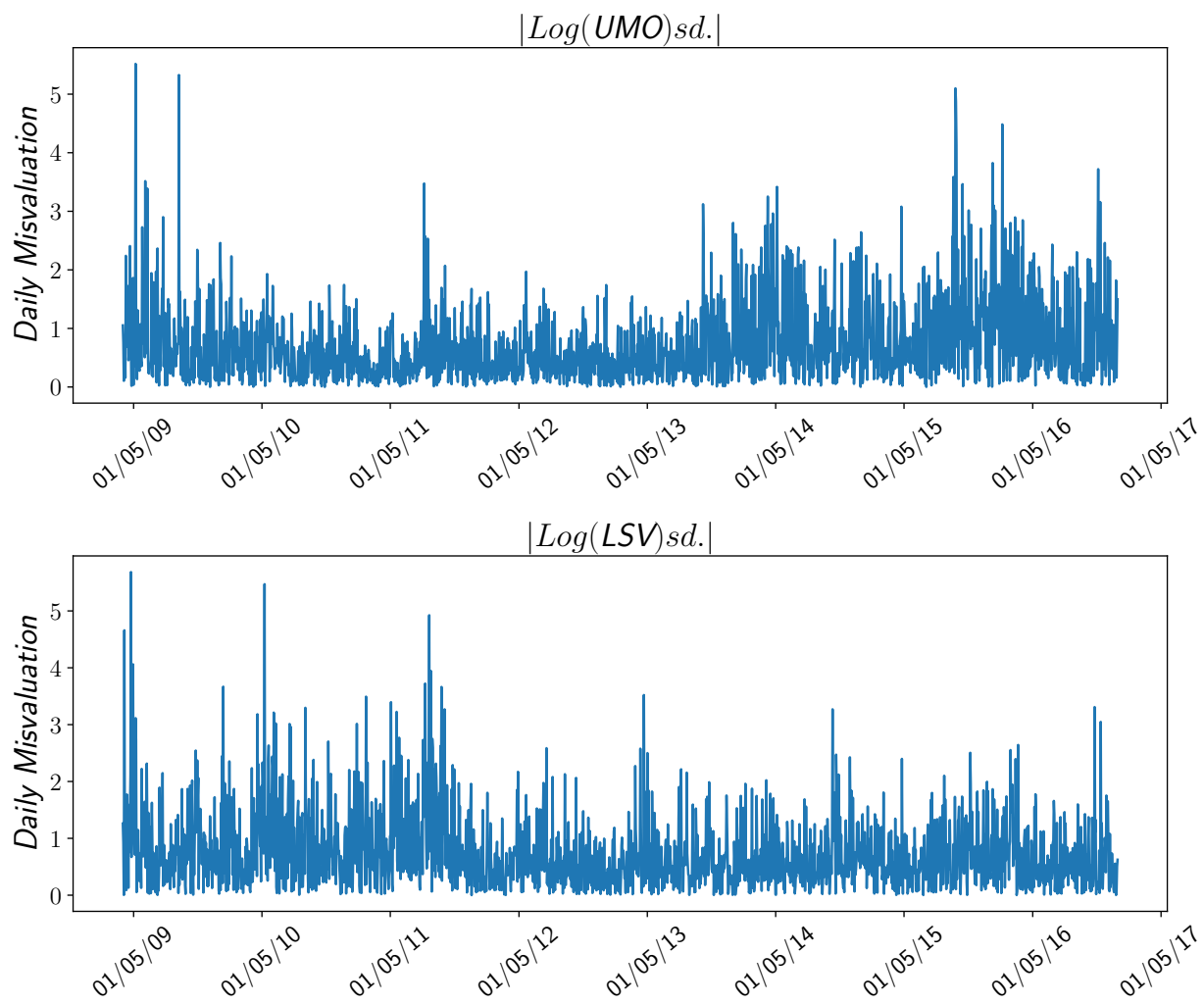

Figure 4: Daily absolute value of the logarithmic return of the $U M O$ and $L S V$ factor rescaled by their mean and standard deviation.

Finally, we investigate whether the $L S V$ factor remains significant in the Fama-French regression (11) augmented with the UMO factor. Therefore, we first consider the following benchmark regression 


$$
\begin{aligned}
R_{U, t}-R_{F, t} & =\beta_{0}+\beta^{\mathrm{M}}\left(R_{M, t}-R_{F, t}\right)+\beta^{\mathrm{SMB}} S M B_{t}+\beta^{\mathrm{HML}} H M L_{t}+\beta^{\mathrm{MOM}} M O M_{t} \\
& +\beta^{\mathrm{RMW}} R M W_{t}+\beta^{\mathrm{CMA}} C M A_{t}+\beta^{\mathrm{UMO}} U M O_{t}+e_{t},
\end{aligned}
$$

and then we take into account the orthogonalized version of $L S V$, provided by regression (9) augmented with the $U M O$ factor, so that it is orthogonal also to $U M O$, i.e.:

$$
\begin{gathered}
R_{U, t}-R_{F, t}=\beta_{0}+\beta^{\mathrm{M}}\left(R_{M, t}-R_{F, t}\right)+\beta^{\mathrm{SMB}} S M B_{t}+\beta^{\mathrm{HML}} H M L_{t}+\beta^{\mathrm{MOM}} M O M_{t} \\
+\beta^{\mathrm{RMW}} R M W_{t}+\beta^{\mathrm{CMA}} C M A_{t}+\beta^{\mathrm{UMO}} U M O_{t}+\beta^{\mathrm{LSV}} L S V_{t}^{\perp}+e_{t} .
\end{gathered}
$$

The results are summarized in Table 13. We observe that the coefficient of $L S V$ factor is still statistical significant even if the $U M O$ factor is included in the regression. In addition, by performing the Likelihood-Ratio-test we obtain that the improvement is sensible, $\chi^{2}=34.102$ e $p$-value $=5.22 e$ 09, which means that the complementary information provided by the $L S V$ factor is relevant to explain abnormal returns of market and to further investigate the misvaluation effect. The $z$-score constitutes a crucial role for the construction of the $L S V$ factor, which highlights how it is essential to incorporate an uncertainty measure in a valuation method.

Table 13: This table reports results from regressions of equation (14) and (15). For the first regression the adjusted- $R^{2}$ is $97.88 \%$, the $A I C$ is -1852.22 and the $B I C$ is -1802.03 . Six-factor(2): the adjusted- $R^{2}$ is $97.91 \%$, the $A I C$ is -1884.32 and the $B I C$ is -1828.55 . Heteroskedasticity and autocorrelation $(H A C)$ robust standard errors are shown in the $S t d$ column. Coefficients resulting to be significant at 10\%, 5\%,1\% and $0.1 \%$ level are marked with '.', '*', '**' and '***' respectively. The number of observation is 1953. The sample is from April 1, 2009 to December 30, 2016.

\begin{tabular}{lllllllll}
\hline & Coeff & Std & t-Statistic & p-value & Coeff & Std & $t$-Statistic & p-value \\
\hline Int & 0.0103 & 0.0034 & 3.0230 & $0.0025^{* *}$ & 0.0118 & 0.0034 & 3.4600 & $0.0006^{* * *}$ \\
$R_{M}-R_{F}$ & 1.0238 & 0.0041 & 248.3900 & $<2 \mathrm{e}-16^{* * *}$ & 1.0238 & 0.0041 & 250.5030 & $<2 \mathrm{e}-16^{* * *}$ \\
$S M B$ & 0.0382 & 0.0073 & 5.2610 & $1.59 \mathrm{e}-07^{* * *}$ & 0.0382 & 0.0072 & 5.3060 & $1.25 \mathrm{e}-07^{* * *}$ \\
$H M L$ & -0.1730 & 0.0091 & -19.0800 & $<2 \mathrm{e}-16^{* * *}$ & -0.1730 & 0.0090 & -19.2420 & $<2 \mathrm{e}-16^{* * *}$ \\
$M O M$ & -0.0538 & 0.0047 & -11.4380 & $<2 \mathrm{e}-16^{* * *}$ & -0.0538 & 0.0047 & -11.5360 & $<2 \mathrm{e}-16^{* * *}$ \\
$R M W$ & 0.1561 & 0.0131 & 11.8970 & $<2 \mathrm{e}-16^{* * *}$ & 0.1561 & 0.0130 & 11.9990 & $<2 \mathrm{e}-16^{* * *}$ \\
$C M A$ & 0.2787 & 0.0147 & 18.9960 & $<2 \mathrm{e}-16^{* * *}$ & 0.2787 & 0.0145 & 19.1580 & $<2 \mathrm{e}-16^{* * *}$ \\
$U M O$ & 0.0407 & 0.0076 & 5.3300 & $1.10 \mathrm{e}-07^{* * *}$ & 0.0408 & 0.0076 & 5.3760 & $8.54 \mathrm{e}-08^{* * *}$ \\
$L S V^{\perp}$ & - & - & - & - & -0.0646 & 0.0110 & -5.8520 & $5.69 \mathrm{e}-09^{* * *}$ \\
\hline
\end{tabular}




\section{Conclusions and future perspective}

In this paper, we propose a framework that can be viewed as a generalization of the traditional DCF model to firm valuation, in which it is provided, at the same time, an estimate of the fair value of a company and a measure of the degree of uncertainty associated. The new approach is named Stochastic Discount Cash Flow method, SDCF in short, where the point estimate of the traditional DCF approach is replaced with a probability distribution of fair values, called fair value distribution. We stress that our approach is invariant to the considered valuation model. We show the importance of a distributional approach to valuation through different exercises.

We introduce a $z$-score as a misvaluation indicator and we assess its quality by testing its predictability for future abnormal stocks returns. Based on the ranking of companies relative misvaluation measure, we form a misvaluation factor by longing undervalued stocks and shortselling overvalued stocks. We denote this factor by $L S V$. We explore the relation between $L S V$ and the other risk-factors routinely used in the financial literature. Our results suggest that $L S V$ is not a redundant factor when used to augment the Fama-French five factor model augmented by the momentum factor, in the sense its high average return is not fully captured by the latter. A simple statistical analysis have showed that $L S V$ is correlated with $S M B$. Armed with this evidence, we examine a six-factor model that replaces $S M B$ with $L S V$ and a seven-factor model where both $S M B$ and $L S V$ are employed. It results that the six-factor model has a better fit than the benchmark regression and that in the last one the $S M B$ becomes redundant. However, after removing from $L S V$ possible collinearity with other market factors, the seven-factor model exhibits robust results compared to the other considered factor models. We note that this exercise complements the work of Chang et al. (2013), which provides evidence on the existence of a misvaluation factor, constructed starting from a relative valuation type model. Also, we compare the $L S V$ with the $U M O$ factor of Hirshleifer and Jiang (2010). We find evidences that $U M O$ and $L S V$ are quite orthogonal and that they remain both significant when included in a Fama-French five factor model augmented by the momentum factor.

The above results confirm the importance of assessing the degree of uncertainty associated with the valuation of a company. Nonetheless, the present study can be extended in several directions that we plan to pursue in future papers. We mention here some possible extensions. a) Motivated by the fact that the DCF is a bottom-up approach, we use univariate models to describe the log-revenues dynamics. A natural extension would be to use multivariate time-series models for the log-revenues, thus exploiting the cross-sectional information. b) The fair value distribution obtained with our method can be compared with or complemented by an implicit measure of fair 
value derived, for instance, from the distribution of prices of call and put options. c) Finally, we could exploit the information provided by the $z$-scores to assign stocks recommendations and build investment strategies. 


\section{A. Description of the DCF Model and of Accounting Variables}

The accounting variables used in the UFCF DCF model are described in Table 14.

Table 14: The table reports a description of some accounting variables employed in the UFCF DCF method.

\begin{tabular}{|c|c|}
\hline Variable & Description \\
\hline$E B I T$ & $\begin{array}{l}\text { Earning Before Interest and Taxes (known also as Operating profit) } \\
\text { which represents total revenues from all of a company operating ac- } \\
\text { tivities, after deducting any sales adjustments, excise taxes and other } \\
\text { expenses incurred from operating activities. }\end{array}$ \\
\hline$D \& A$ & $\begin{array}{l}\text { Depreciation and Amortization which refers to the amount of expense } \\
\text { charged by a company to cancel the cost of a plant or machinery over } \\
\text { its useful life, giving consideration to wear and tear, obsolescence and } \\
\text { salvage value together with a non-cash expense incurred due to the } \\
\text { amortization of intangible fixed assets and goodwill. }\end{array}$ \\
\hline$E B I T D A$ & Earning Before Interest, Taxes, Depreciation, and Amortization. \\
\hline Marginal Tax Rate & $\begin{array}{l}\text { It represents the amount of tax which we have to deduct from earnings. } \\
\text { For sake of simplicity, we will denote it by } \tau_{0} \text {. }\end{array}$ \\
\hline NOPAT & $\begin{array}{l}\text { Net Operating Profit After Tax, which is defined, at each time instant, } \\
\text { as the difference between } E B I T D A \text { and } D \& A \text {, multiplied by }\left(1-\tau_{0}\right) \text {. }\end{array}$ \\
\hline$W C$ & $\begin{array}{l}\text { Working Capital which is defined as the difference between current } \\
\text { assets and current liabilities of a company so that it represents a } \\
\text { measure of liquidity and efficiency. We will denote by } \Delta W C_{t}=W C_{t}- \\
W C_{t-1} \text { the Change in the } W C \text {. }\end{array}$ \\
\hline$C A P E X$ & $\begin{array}{l}\text { Capital Expenditure which includes all expenditures that are not } \\
\text { treated as an expense on the income statement when they are in- } \\
\text { curred, such as the costs for the development of software which are } \\
\text { capitalized at the time of development, and amortized later, when } \\
\text { such software is actually implemented for production. }\end{array}$ \\
\hline$T D$ & $\begin{array}{l}\text { Total Debt Outstanding which represents the total interest-bearing } \\
\text { debt outstanding. }\end{array}$ \\
\hline CsI & $\begin{array}{l}\text { Cash and Short-term Investments which represents short-term, highly } \\
\text { liquid investments that are both readily convertible to known amounts } \\
\text { of cash together with cash on hand and any investments in debt and } \\
\text { equity securities with maturity of one year or less. }\end{array}$ \\
\hline$M I$ & $\begin{array}{l}\text { Minority Interest which represents accumulated interest for minority } \\
\text { shareholders in subsidiaries that are less than } 100 \text { percent owned by } \\
\text { the reporting parent company. }\end{array}$ \\
\hline$P S$ & Preferred Stock which represents the value of preferred shares. \\
\hline
\end{tabular}


In Table 15 we report the average and standard deviation of WACC computed among the firms along with the perpetual growth rate $g$.

Table 15: Summary statistics of the WACC for each quarter, as well as of the perpetual growth rate.

\begin{tabular}{l|lllll}
\hline & $2017-12-31$ & $2017-09-30$ & $2017-06-30$ & $2017-03-30$ & $2016-12-30$ \\
\hline Average WACC & 7.26 & 6.88 & 6.65 & 6.62 & 7.10 \\
Std. Dev. WACC & 1.42 & 1.40 & 1.36 & 1.34 & 1.47 \\
$\mathrm{~g}$ & 2.54 & 2.07 & 1.82 & 1.81 & 1.94 \\
\hline & $2016-09-30$ & $2016-06-30$ & $2016-03-30$ & $2015-12-30$ & $2015-09-30$ \\
\hline Average WACC & 6.82 & 6.45 & 6.51 & 6.44 & 6.57 \\
Std. Dev. WACC & 1.43 & 1.53 & 1.51 & 1.44 & 1.40 \\
g & 1.61 & 1.13 & 1.24 & 1.37 & 1.59 \\
\hline & $2015-06-30$ & $2015-03-30$ & $2014-12-30$ & $2014-09-30$ & $2014-06-30$ \\
\hline Average WACC & 6.72 & 6.68 & 5.97 & 6.09 & 6.20 \\
Std. Dev. WACC & 1.55 & 1.52 & 1.34 & 1.32 & 1.36 \\
g & 1.55 & 1.52 & 1.45 & 1.60 & 1.70 \\
\hline & $2014-03-30$ & $2013-12-30$ & $2013-09-30$ & $2013-06-30$ & $2013-03-30$ \\
\hline Average WACC & 6.16 & 6.81 & 6.78 & 6.81 & 6.31 \\
Std. Dev. WACC & 1.44 & 1.66 & 1.80 & 1.81 & 1.79 \\
g & 1.66 & 1.60 & 1.44 & 1.51 & 0.92 \\
\hline & $2012-12-30$ & $2012-09-30$ & $2012-06-30$ & $2012-03-30$ & $2011-12-30$ \\
\hline Average WACC & 6.48 & 6.34 & 6.29 & 6.44 & 5.81 \\
Std. Dev. WACC & 1.81 & 1.74 & 1.70 & 1.75 & 1.46 \\
g & 0.83 & 0.69 & 0.67 & 0.79 & 0.90 \\
\hline & $2011-09-30$ & $2011-06-30$ & $2011-03-30$ & $2010-12-30$ & $2010-09-30$ \\
\hline Average WACC & 5.81 & 6.07 & 6.67 & 6.08 & 5.52 \\
Std. Dev. WACC & 1.44 & 1.47 & 1.51 & 1.23 & 1.19 \\
g & 0.95 & 1.15 & 1.86 & 2.12 & 1.49 \\
\hline & $2010-06-30$ & $2010-03-30$ & $2009-12-30$ & $2009-09-30$ & $2009-06-30$ \\
\hline Average WACC & 5.53 & 6.17 & 8.01 & 7.89 & 7.85 \\
Std. Dev. WACC & 1.19 & 1.28 & 1.83 & 1.84 & 1.82 \\
g & 1.55 & 2.25 & 2.42 & 2.30 & 2.47 \\
\hline & $2009-03-30$ & & & & \\
\hline Average WACC & 7.53 & & & & \\
Std. Dev. WACC & 1.80 & & & & \\
g & 2.23 & & & & \\
\hline & & & & & \\
\hline
\end{tabular}




\section{B. Empirical Results of Section 2}

The coefficient of determination is on average greater than 0.90 , which assesses the goodness of fit of the linear regression of $\overline{C F}_{t}$ on $R E V_{t}$. As regards the model misspecification, we check the normality and the autocorrelation of the standardized residuals. The Kolmogorov-Smirnov test fails to reject the assumption of normality of the standardized residuals for about the $56 \%$ of the firms in our universe at 0.01 level. Also, there is no evidence of serial correlations for about $72 \%$ of the firms using the Ljung-Box statistic. Figure 5 exhibits, in each row, an example of sample autocorrelations of the standardized residuals and of theirs squares, as well as the quantile-quantile plots.

Then, we assess the goodness of fit of Model 1, Model 2 and Model 3 described in Section 2, In order to do so, we proceed as follows:

i) If the time series of the log-revenues' increments is stationary we use Model 1 and the performance of ARIMA-based models is assessed by looking at the usual coefficient of the determination.

ii) On the contrary, in case of non-stationarity, i.e. either Model 2 or Model 3 is selected, we proceed in the following way. Let $\bar{y}$ be the sample average of the log-revenues computed over a predetermined time period, and $\mu_{t \mid p r e d}=\mathbb{E}\left[\mu_{t} \mid \mathcal{F}_{t-1}\right]$ be the Kalman filter prediction of the state variable $\mu$ at time $t$. If $T$ is the length of the considered time-series and $K$ the number of explanatory variables, then we define the adjusted coefficient of determination $R_{a d j}^{2}$ as:

$$
R_{a d j}^{2}:=1-\left(1-R^{2}\right) \frac{T-1}{T-K-1},
$$

where

$$
R^{2}:=1-\frac{S S_{r e s}}{S S_{t o t}}
$$

with $S S_{\text {res }}=\sum_{t=1}^{T}\left(y_{t}-\mu_{t \mid p r e d}\right)^{2}$ and $S S_{t o t}=\sum_{t=1}^{T}\left(y_{t}-\bar{y}\right)^{2}$.

The following results are obtained by the average on the whole sample considered (FQ4 2008- FQ4 2017). For the $71 \%$ of the firms in the sample Model 1 is the model that present the best goodness of fit. Of the remaining, only the $1.5 \%$ of firms have a log-revenues process that is well fitted by Model 2. Regardless the model selection we found that the coefficient of determination is greater than 0.90 on average among the sample period and firm cross-section. 

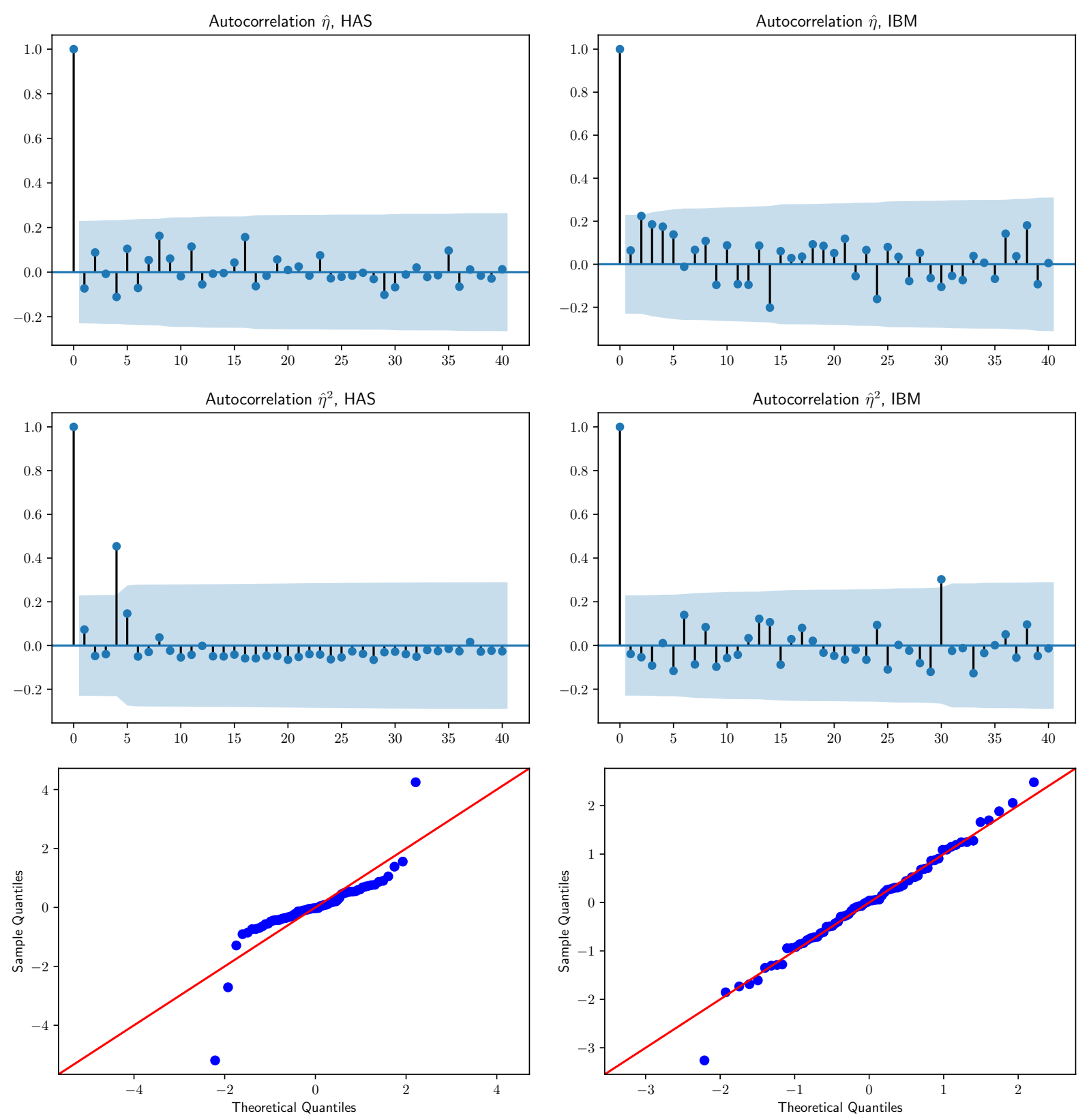

Figure 5: The Figure represents examples of sample autocorrelation of the standardized prediction errors for the regression in Eq. (5) (first row), for their squares (second row), as well as their quantile-quantile (third row) plots. 


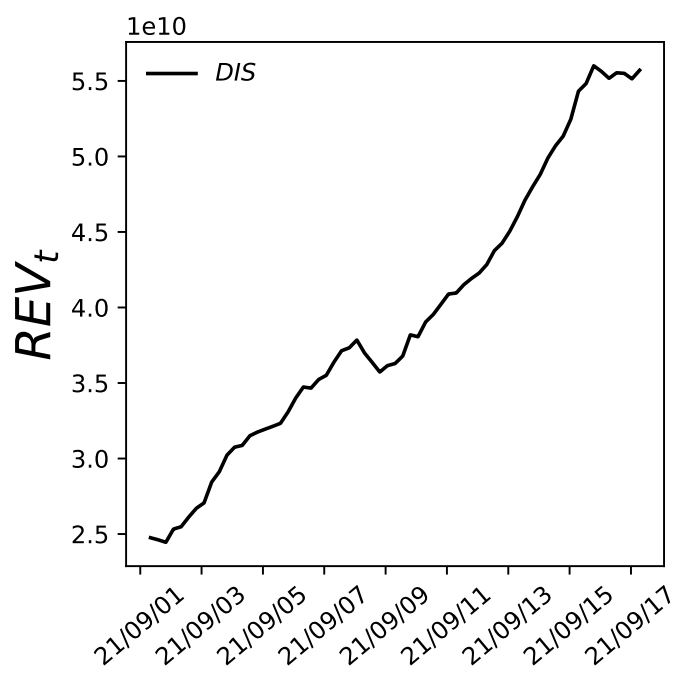

Date

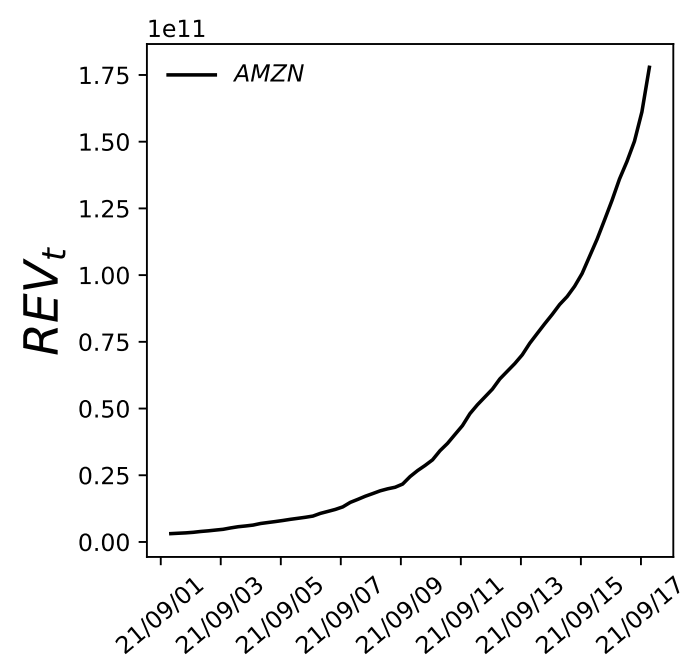

Date

Figure 6: The Figure represents two examples of the dynamic of the Revenues well fitted by Model 1 (Left Panel) and Model 3 (Right Panel). Model 1: Disney (ticker DIS). Model 3: Amazon (ticker AMZN).

The plots in Figure 6 report the typical dynamics of the revenues process in Model 1 (left panel) and Model 2-3 (right panel). Examples of firms for which the latter models have been selected are Amazon (ticker AMZN) and Booking (ticker BKNG).

Models 2 and 3 assume that shocks are i.i.d. with a zero-mean Gaussian distribution. Following Durbin and Koopman (2012) we check for a possible misspecification of these models by looking at the time series of the standardized one-step ahead forecast errors $\hat{\eta}$ and we refer to Durbin and Koopman (2012) for further details on this definition. In case of correct specification of the models, the latter should be i.i.d. and normally distributed. Figure 7 shows, in each row, an example of sample autocorrelations of $\hat{\eta}_{t}$ and $\hat{\eta}_{t}^{2}$, as well as quantile-quantile plots for $\hat{\eta}_{t}$. We only note some very weak heteroskedasticity of $\hat{\eta}_{t}$ and a slight deviation from normality in the tails. Similar results are obtained also for the other firms and available upon request. In detail, the $74 \%$ of the firms in the sample exhibit $\hat{\eta}_{t}$ with a distribution that is not statistically different from the Gaussian at the 0.01 confidence level according to the Kolmogorov-Smirnov test. Also, the $\hat{\eta}_{t}$ of the $76 \%$ (resp. 78\%) of the firms do not exhibit significant serial autocorrelation at the 0.01 confidence level according to the Ljung-Box test performed at lag 1 (resp. 10). We argue that the proposed framework represents an optimal trade-off between a model with a perfect statistical fit of the data and a model that have clear advantages in terms of practical implementability. 

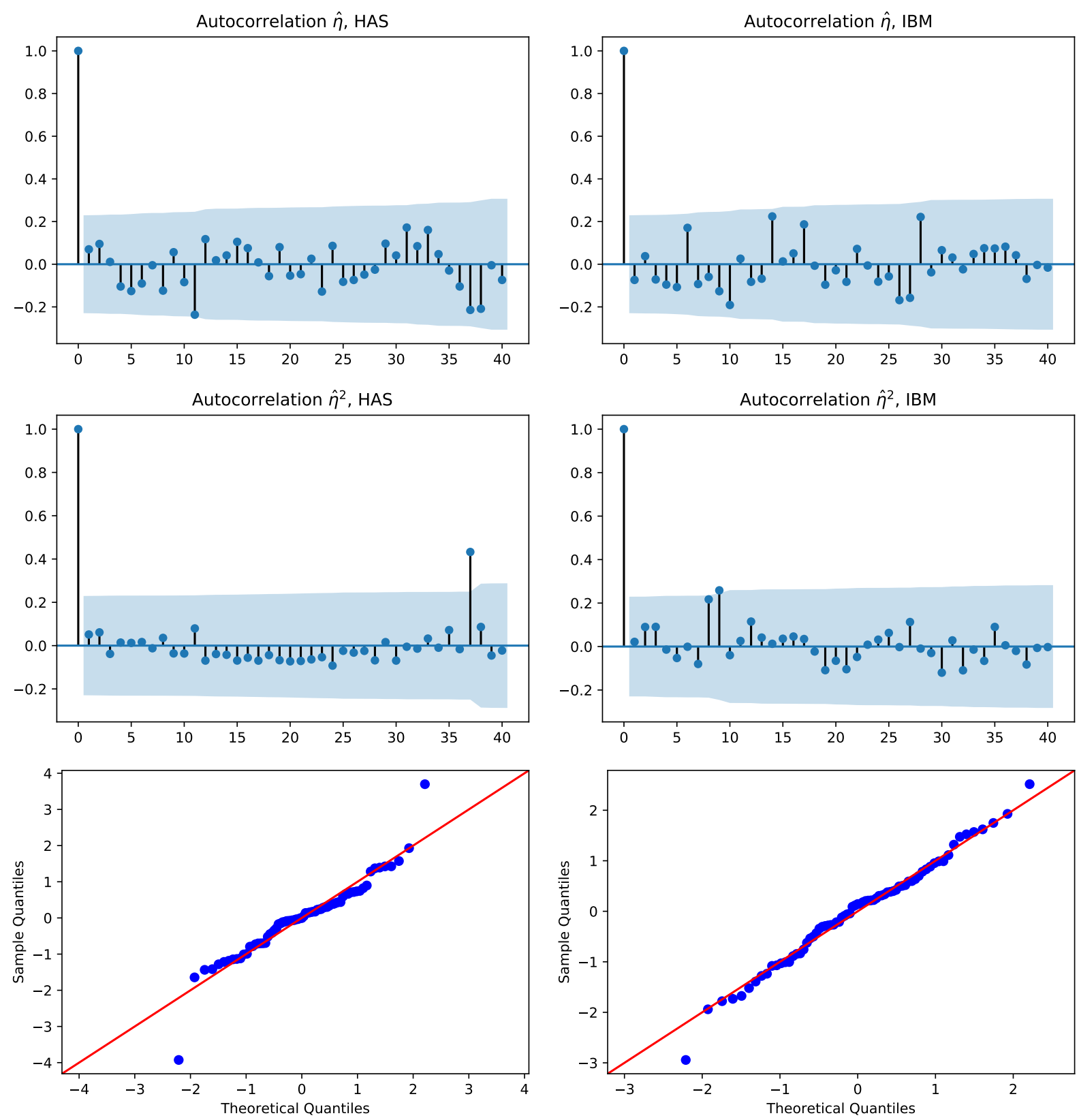

Figure 7: The Figure represents examples of sample autocorrelation of $\hat{\eta}$ (first row) and $\hat{\eta}^{2}$ (second row), as well as quantile-quantile plots (third row) for $\hat{\eta}$. The left plots are referred to Hasbro (ticker HAS), while the right ones to IBM (ticker IBM). 
Finally, we present results on the predictive ability of Model 1, Model 2 and Model 3 for our sample firms by comparing it with that of a simple autoregressive model of order one $\mathrm{AR}(1)$, which is described by the following dynamic: $y_{t}=\alpha y_{t-1}+\varepsilon_{t}$ where $|\alpha| \leq 1$ and $\varepsilon_{t} \stackrel{d}{\sim} \mathcal{N}\left(0, \sigma_{\varepsilon}^{2}\right)$. We start by estimating all models over the period December 1992 - March 2009 and by making predictions for the next 20 quarters (i.e. for the next 5 years). We then add the most recent observation, we shift the estimation period by one quarter and we make predictions for the next 20 quarters, and so on and so forth till the first quarter of 2013 ${ }^{12}$ We compute the following (relative) error metric for each firm $j$ and each estimation period $e$ :

$$
\mathrm{RMSQ}_{j}^{e}:=\frac{\mathrm{MSE}_{j, \text { our }}}{\mathrm{MSE}_{j, \mathrm{AR}(1)}},
$$

where MSE stands for Mean Square Error and our is either Model 1, Model 2 or Model 3. The mean square error is defined in the natural way as MSE $:=\frac{1}{H} \sum_{h=1}^{H}\left(y_{t+h}-\hat{y}_{t+h}\right)^{2}$, where $H=20$ and $y$ and $\hat{y}$ denotes the actual and the predicted value, respectively. For conciseness, for each estimation period $e$ we compute the average across-firms of the $\mathrm{RMSQ}_{j}^{e}$. In addition, we test whether our models perform better than the $\mathrm{AR}(1)$ : a negative average of $\log \left(\mathrm{RMSQ}_{j}\right)$ means that our models have a MSE smaller than the that of the $\mathrm{AR}(1)$. Table 16 reports the average of the logarithm of $\mathrm{RMSQ}_{j}$ among the quarters. We observe that the average $\log \left(\mathrm{RMSQ}_{j}^{e}\right)$ is always negative and statistically significant for all quarters, with an exception of the last quarters of 2009 and the first of 2010, thus confirming that a more complex dynamics than the simple $\mathrm{AR}(1)$ one is necessary. Also, for each quarter, we compute the percentage of firms for which $\mathrm{RMSQ}_{j}<1$ and the results are reported in Table 17 . On average, for $65 \%$ of companies our models perform better than the $\operatorname{AR}(1)$.

Table 16: Average $\log \left(\mathrm{RMSQ}_{j}\right)$ computed across firms for all the quarters. Values that result to be significant at $10 \%, 5 \%, 1 \%$ and $0.1 \%$ level are marked with '.', '*', ' $* *$ ' and ' $* * *$ ' respectively.

\begin{tabular}{llllll}
\hline $2009-03-31$ & $2009-06-30$ & $2009-09-30$ & $2009-12-31$ & $2010-03-31$ & $2010-06-30$ \\
\hline$-0.61^{* * *}$ & $-0.33^{*}$ & $0.31^{*}$ & $0.43^{* *}$ & 0.14 & $-0.72^{* * *}$ \\
\hline $2010-09-30$ & $2010-12-31$ & $2011-03-31$ & $2011-06-30$ & $2011-09-30$ & $2011-12-31$ \\
\hline$-0.81^{* * *}$ & $-0.89^{* * *}$ & $-0.84^{* * *}$ & $-0.82^{* * *}$ & $-0.87^{* * *}$ & $-0.78^{* * *}$ \\
\hline $2012-03-31$ & $2012-06-30$ & $2012-09-30$ & $2012-12-31$ & $2013-03-31$ & \\
\hline$-0.59^{* * *}$ & $-0.54^{* *}$ & $-0.66^{* * *}$ & $-0.59 * * *$ & $-0.68 * * *$ & \\
\hline
\end{tabular}

\footnotetext{
${ }^{12}$ We remind that the data sample for the revenues end in the first quarter of 2018 .
} 
Table 17: Percentage of firms $j$ such that $\mathrm{RMSQ}_{j}<1$ among the all quarters. On average $65 \%$ companies have a RMSQ which is smaller than 1 .

\begin{tabular}{llllll}
\hline $2009-03-31$ & $2009-06-30$ & $2009-09-30$ & $2009-12-31$ & $2010-03-31$ & $2010-06-30$ \\
\hline $65 \%$ & $58.57 \%$ & $45.71 \%$ & $44.29 \%$ & $48.57 \%$ & $70.00 \%$ \\
\hline $2010-09-30$ & $2010-12-31$ & $2011-03-31$ & $2011-06-30$ & $2011-09-30$ & $2011-12-31$ \\
\hline $74.29 \%$ & $72.14 \%$ & $75.71 \%$ & $72.14 \%$ & $74.29 \%$ & $68.57 \%$ \\
\hline $2012-03-31$ & $2012-06-30$ & $2012-09-30$ & $2012-12-31$ & $2013-03-31$ & \\
\hline $63.57 \%$ & $65.71 \%$ & $67.86 \%$ & $64.29 \%$ & $68.57 \%$ & \\
\hline
\end{tabular}




\section{References}

Ali, M., R. El-Haddadeh, T. Eldabi, and E. Mansour (2010). Simulation discounted cash flow valuation for internet companies. International Journal of Business Information Systems 6(1), $18-33$.

Ardia, D. and K. Boudt (2018). The Peer Ratios Performance of Hedge Funds. Journal of Banking and Finance 87, 351.

Brown, L. D., A. C. Call, M. B. Clement, and N. Y. Sharp (2015). Inside the Black Box of sell-side financial analysts. Journal of Accounting Research 53(1), 1-47.

Carhart, M. M. (1997). On Persistence in Mutual Fund Performance. The Journal of Jinance 52(1), $57-82$.

Casey, C. (2001). Corporate valuation, capital structure and risk management: A stochastic DCF approach. European Journal of Operational Research 135(2), 311-325.

Chang, E. C., Y. Luo, and J. Ren (2013). Pricing deviation, misvaluation comovement, and macroeconomic conditions. Journal of Banking \& Finance 37(12), 5285-5299.

Damodaran, A. (2007). Valuation Approaches and Metrics: A Survey of the Theory and Evidence. Foundations and Trends® in Finance 1(8), 693-784.

Damodaran, A. (2010). Applied corporate finance. John Wiley \& Sons.

Damodaran, A. (2012). Investment valuation: Tools and techniques for determining the value of any asset. John Wiley \& Sons.

Dayananda, D., R. Irons, S. Harrison, J. Herbohn, and P. Rowland (2002). Capital budgeting: financial appraisal of investment projects. Cambridge University Press.

Durbin, J. and S. J. Koopman (2012). Time series analysis by state space methods, Volume 38. Oxford University Press.

Fama, E. F. and K. R. French (1993). Common risk factors in the returns on stocks and bonds. Journal of Financial Economics 33(1), 3-56.

Fama, E. F. and K. R. French (2015). A five-factor asset pricing model. Journal of Financial Economics 116(1), 1-22. 
French, N. and L. Gabrielli (2005). Discounted cash flow: accounting for uncertainty. Journal of Property Investment \& Finance 23(1), 75-89.

Gimpelevich, D. (2011). Simulation-based excess return model for real estate development. Journal of Property Investment \& Finance.

Harvey, A. C. (1990). Forecasting, structural time series models and the Kalman filter. Cambridge university press.

Hirshleifer, D. and D. Jiang (2010). A Financing-Based Misvaluation Factor and the Cross-Section of Expected Returns. The Review of Financial Studies 23(9), 3401-3436.

Koller, T., M. Goedhart, D. Wessels, et al. (2010). Valuation: measuring and managing the value of companies, Volume 499. john Wiley and sons.

Kruschwitz, L. and A. Löffler (2006). Discounted cash flow: a theory of the valuation of firms. John Wiley \& Sons.

Ledoit, O. and M. Wolf (2008). Robust performance hypothesis testing with the Sharpe ratio. Journal of Empirical Finance 15(5), 850-859.

Merton, R. C. (1973). An Intertemporal Capital Asset Pricing Model. Econometrica 41(5), 867-887.

Razgaitis, R. (2009). Valuation and dealmaking of technology-based intellectual property: Principles, methods and tools. John Wiley \& Sons.

Samis, M. and G. A. Davis (2014). Using Monte Carlo simulation with DCF and real options risk pricing techniques to analyse a mine financing proposal. International Journal of Financial Engineering and Risk Management 3 1(3), 264-281.

Viebig, J., T. Poddig, and A. Varmaz (2008). Equity valuation: models from leading investment banks, Volume 434. John Wiley \& Sons. 